
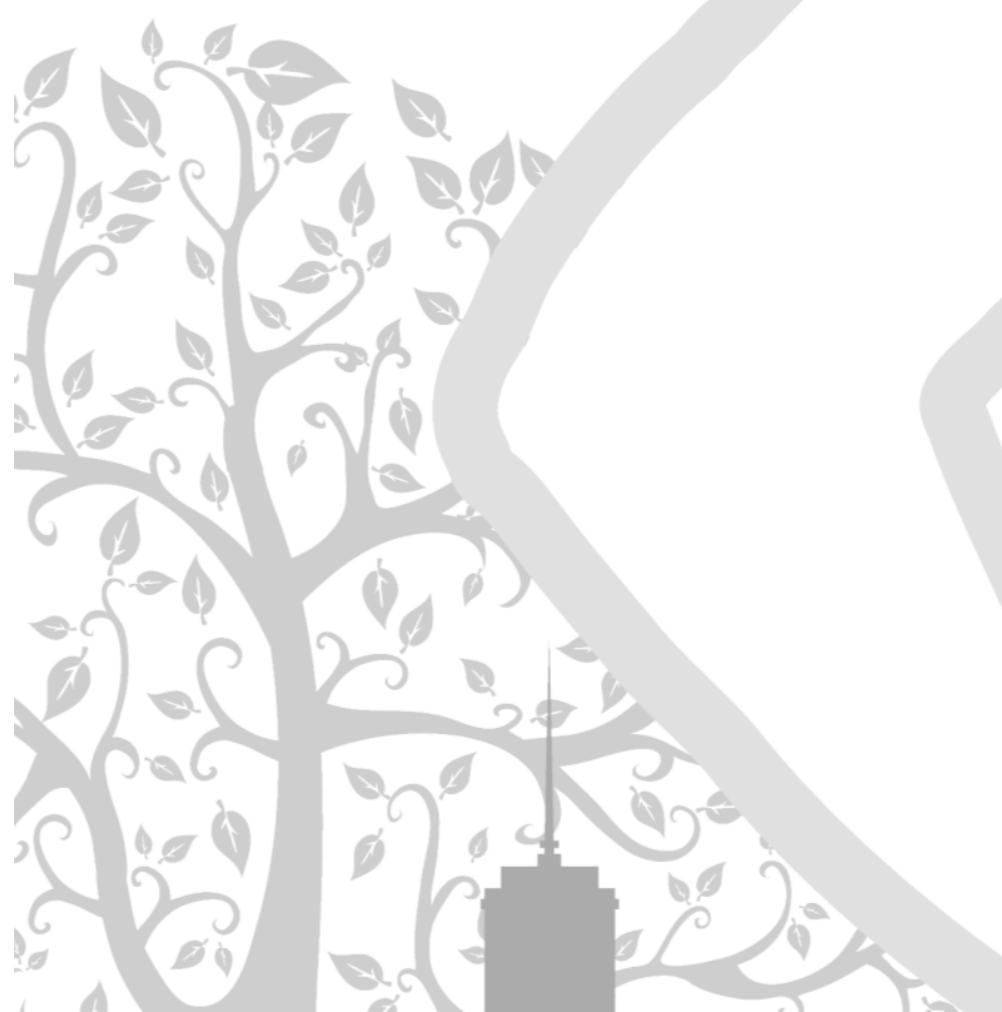

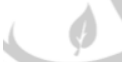
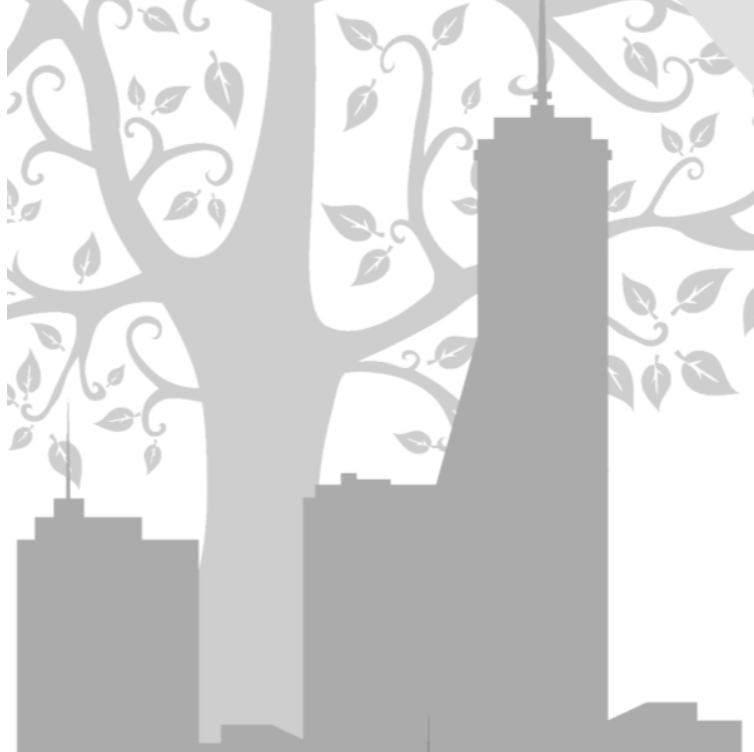


\section{Common variants in DGKK are strongly associated with risk of hypospadias}

Loes F.M. van der Zanden ${ }^{1,2}$, Iris A.L.M. van Rooij ${ }^{1}$, Wout F.J. Feitz ${ }^{3}$, Jo

Knight $^{4,5}$, A. Rogier T. Donders ${ }^{1}$, Kirsten Y. Renkema ${ }^{2}$, Ernie M.H.F. Bongers $^{2}$, Sita H.H.M. Vermeulen ${ }^{1,2}$, Lambertus A.L.M. Kiemeney ${ }^{1,3}$, Joris A. Veltman ${ }^{2}$, Alejandro Arias-Vásquez ${ }^{2,6}$, Xufeng Zhang ${ }^{7}$, Ellen Markljung ${ }^{7}$, Liang Qiao ${ }^{8}$, Laurence S. Baskin ${ }^{8}$, Agneta Nordenskjöld ${ }^{7,9}$, Nel Roeleveld ${ }^{1,10}$, Barbara Franke $2,6,10$, Nine V.A.M. Knoers ${ }^{2,10}$

${ }^{1}$ Department of Epidemiology, Biostatistics and HTA, Radboud University Nijmegen Medical Centre, Nijmegen, The Netherlands, ${ }^{2}$ Department of Human Genetics, Radboud University Nijmegen Medical Centre, Nijmegen, The Netherlands, ${ }^{3}$ Department of Urology, Radboud University Nijmegen Medical Centre, Nijmegen, The Netherlands, ${ }^{4}$ Division of Genetics and Molecular Medicine, King's College London School of Medicine, London, United Kingdom

${ }^{5}$ National Institute for Health Research (NIHR), Biomedical Research Centre, Guy's and St.

Thomas' NHS Foundation Trust and King's College London, London, United Kingdom, ${ }^{6}$ Department of Psychiatry, Donders Institute for Brain, Cognition and Behavior, Radboud University Nijmegen Medical Centre, Nijmegen, The Netherlands, ${ }^{7}$ Department of Women's and Children's Health and Center of Molecular Medicine, Karolinska Institutet, Stockholm, Sweden, ${ }^{8}$ Department of Urology, University of California, San Francisco, USA

${ }^{9}$ Department of Pediatric Surgery, Astrid Lindgren Children Hospital, Karolinska University Hospital, Stockholm, Sweden, ${ }^{10}$ These authors contributed equally to this work

\section{Corresponding author}

Barbara Franke, PhD Department of Human Genetics, 855 Radboud University Nijmegen Medical Centre P.O. Box 9101 6500 HB Nijmegen The Netherlands Tel: +31 243614017 Fax: +31 243668752 E-mail: B.Franke@antrg.umcn.nl 


\section{Abstract}

Hypospadias is a common congenital malformation of the male external genitalia. We performed a genome-wide association study using pooled DNA from 436 individuals with hypospadias (cases) and 494 controls of European descent and selected the highest ranked SNPs for individual genotyping in the discovery sample, an additional Dutch sample of 133 cases and their parents, and a Swedish series of 266 cases and 402 controls. Individual genotyping of two SNPs (rs1934179 and rs7063116) in DGKK, encoding diacylglycerol kinase $\mathrm{k}$, produced compelling evidence for association with hypospadias in the discovery sample (allelespecific odds ratio $(O R)=2.5, P=2.5 \times 10^{-11}$ and $O R=2.3, P=2.9 \times 10^{-9}$, respectively) and in the Dutch $\left(\mathrm{OR}=3.9, P=2.4 \times 10^{-5}\right.$ and $\left.\mathrm{OR}=3.8, P=3.4 \times 10^{-5}\right)$ and Swedish $\left(\mathrm{OR}=2.5, P=2.6 \times 10^{-8}\right.$

and $\mathrm{OR}=2.2, P=2.7 \times 10^{-6}$ ) replication samples. Expression studies showed expression of $D G K K$ in preputial tissue of cases and controls, which was lower in carriers of the risk allele of rs1934179 $(P=0.047)$. We propose $D G K K$ as a major risk gene for hypospadias. 


\section{Article}

Hypospadias is a common congenital hypoplasia of the penis, affecting approximately 1 in 750 births in Europe (see URLS). Due to developmental arrest of urethral fusion, the urethral opening is displaced along the ventral side of the penis. The opening can be located glandular, penile or even more posterior in the scrotum or perineum. Although most children with this condition undergo surgery in their second year of life, serious medical, social and sexual problems may still exist later in life. Hypospadias shows familial clustering ${ }^{1}$, pointing toward genetic factors being important in its etiology ${ }^{2}$. Hypotheses about the multifactorial etiology of hypospadias mainly focus on hormonal disturbances. Polymorphisms in endocrine-related genes have been associated with hypospadias ${ }^{3-11}$. However, most of these associations have been found in small studies and were not replicated in the series used in the present study ${ }^{12}$. Therefore, our understanding of the molecular pathways leading to hypospadias is incomplete.

With the availability of SNP microarrays, genome-wide association studies (GWASs) have become feasible in elucidating the genetic basis of common complex disorders. Large sample sizes are needed in GWASs to detect genetic factors with modest effects on disease risk, having substantial implications in terms of costs. A useful solution is offered by DNA pooling, which has been proven to be feasible and accurate $e^{13-15}$.

To identify genetic variants contributing to hypospadias susceptibility, we performed the first GWAS for this malformation using pooled DNA samples. We included 436 cases of European descent with isolated anterior or middle hypospadias from the AGORA (Aetiologic research into Genetic and Occupational/environmental Risk factors for Anomalies in children) project (Supplementary Fig. 1 and Supplementary Table 1) and 494 unaffected male controls of European descent from the Nijmegen Biomedical Study. In this discovery sample, we allelotyped 906,600 SNPs in duplicate using Affymetrix GeneChip 6.0 microarrays and calculated allele frequencies using $k$-corrected signal intensities (see Supplementary Note). The worst performing $5 \%$ of measurements, indicated by the biggest differences between the allele frequency estimates from the duplicate measurements, were excluded. Furthermore, we excluded SNPs based on several quality control criteria, such as high variance in case or control pools and minor allele frequencies (MAF) below 5\%. A total of 574,400 SNPs passed quality control steps and were included in the analyses. We selected the 50 highest ranked SNPs based on the standard $\chi^{2}$ statistic and a modified $\chi^{2}$ statistic $^{16}$ applied to the raw and $k$-corrected allele frequency estimates. Of these 50 SNPs, we chose 20 based on several criteria, such as location near a gene and MAF (Supplementary Table 2). Seven of these 20 SNPs were located in the X-chromosomal gene $D G K K$, encoding diacylglycerol kinase $\mathrm{k}$. As most SNPs in this gene are in strong linkage disequilibrium (LD) with each other (Supplementary Fig. 2), we selected the intronic SNP that tagged the most other SNPs (rs1934179) for individual genotyping in the 
discovery sample, as well as a potentially regulatory SNP in the 5' upstream region (rs7063116). Furthermore, nine SNPs in other genes were individually genotyped (Supplementary Table 3).

Table 1. Association of hypospadias with SNPs in DGKK in the discovery sample, the Dutch replication sample and the Swedish replication sample.

\begin{tabular}{|c|c|c|c|c|c|c|}
\hline \multirow{2}{*}{ Study population } & \multicolumn{3}{|c|}{ rs1934179 in DGKK } & \multicolumn{3}{|c|}{ rs7063116 near DGKK } \\
\hline & OR & $(95 \%$ Cl) & $\chi^{2} P$ & OR & $(95 \% \mathrm{Cl})$ & $\chi^{2} P$ \\
\hline Dutch discovery sample & 2.46 & $(1.88-3.21)$ & $2.5 \times 10^{-11}$ & 2.25 & $(1.72-2.96)$ & $2.9 \times 10^{-9}$ \\
\hline Dutch replication sample & 3.92 & $(2.08-7.38)$ & $2.4 \times 10^{-5}$ & 3.83 & $(2.03-7.24)$ & $3.4 \times 10^{-5}$ \\
\hline Swedish replication sample & 2.48 & $(1.80-3.42)$ & $2.6 \times 10^{-8}$ & 2.16 & $(1.56-2.99)$ & $2.7 \times 10^{-6}$ \\
\hline
\end{tabular}

OR, odds ratio; $\mathrm{Cl}$, confidence interval.

Individual genotyping was completed with a success rate of $\geq 99 \%$. All genotype frequencies in the controls were in Hardy-Weinberg equilibrium $(P>0.05)$. Both SNPs in DGKK showed genome-wide significant association in the discovery sample (OR for the A (risk) allele of these $X$-chromosomal SNPs in our male sample $=2.5, P=2.5 \times 10^{-11}$ for $\mathrm{rs} 1934179$ and $\mathrm{OR}=2.3, P=$ $2.9 \times 10^{-9}$ for rs7063116) (Table 1). These results were validated by genotyping the parents of the cases using the transmission disequilibrium test, a method robust to population stratification (Table 2). Eight of the other nine SNPs showed suggestive association with hypospadias $(P<0.05)$ (Supplementary Table 4$)$.

Table 2. Association of hypospadias with SNPs in DGKK in cases in the discovery sample and their parents.

\begin{tabular}{lcclllc}
\hline SNP & Minor allele $^{\text {a }}$ & T & NT & OR & $\mathbf{( 9 5 \% ~ C l ) ~}$ & $\chi^{2} \boldsymbol{P}$ \\
\hline rs1934179 in DGKK & A & 147 & 58 & 2.53 & $(1.87-3.43)$ & $2.0 \times 10^{-9}$ \\
rs7063116 near DGKK & A & 134 & 65 & 2.06 & $(1.53-2.77)$ & $1.7 \times 10^{-6}$ \\
\hline
\end{tabular}

${ }^{a}$ The least frequent allele in the controls of the discovery sample; NT, minor allele not transmitted; $T$, minor allele transmitted; OR, odds ratio; $\mathrm{Cl}$, confidence interval.

For the ten associated SNPs, we subsequently attempted replication in an additional Dutch sample of 133 anterior or middle hypospadias cases of European descent and their parents. Seven SNPs showed similar ORs in this sample compared to the discovery sample, although most of these SNPs did not reach statistical significance, probably due to the small number of heterozygous parents. The only exceptions to this were the SNPs in DGKK, in which the same A alleles were again strongly associated with hypospadias (OR $=3.9, P=2.4 \times 10^{-5}$ for $\mathrm{rs} 1934179$ and $\mathrm{OR}=3.8, P=3.4 \times 10^{-5}$ for rs7063116) (Table 1 and Supplementary Table 5). A second replication in a Swedish cohort of 266 anterior or middle hypospadias cases and 402 male controls convincingly confirmed the associations with the A alleles of the SNPs in DGKK (OR = 
2.5, $P=2.6 \times 10^{-8}$ for $\mathrm{rs} 1934179$ and $\mathrm{OR}=2.2, P=2.7 \times 10^{-6}$ for rs7063116), whereas associations with the other eight SNPs did not reach statistical significance (Table 1 and Supplementary Table 6). We then performed a meta-analysis with both the discovery sample and the two replication samples (Supplementary Table 7). In addition to the SNPs in DGKK, SNPs in PPARGC1B ( $r$ 4705372) and GRID1 (rs1880386) reached statistical significance in this analysis after correcting the critical $P$ value for multiple testing (critical Bonferroni $P<0.005$ ).

The pathogenesis of hypospadias probably includes many causal factors. We calculated the population attributable fraction (PAF) for hypospadias of rs 1934179 in DGKK to be $32 \%$ in the Dutch population and $31 \%$ in the Swedish population, mean ing that the variant underlying the association between rs1934179 in DGKK and hypospadias is one of the causal factors in nearly one third of hypospadias cases. As a comparison, the PAF for APOE in Alzheimer's disease is $26 \%$ (ref. 17), and that association is one of the strongest and best known genetic associations reported for a multifactorial disorder. However, the PAF calculated for hypospadias is based on data from our study only, and independent population-based studies should be performed to verify the validity of the estimate.

$D G K K$ encodes a human type II diacylglycerol kinase ${ }^{18}$. Diacylglycerol kinases modulate the balance between diacylglycerol and phosphatidic acid, two signaling lipids, thereby playing an important role in signal transduction. DGKK mRNA is most abundant in testis and placenta ${ }^{18}$. Although DGKK has not previously been associated with hypospadias and there are other genes in close proximity to it, we suggest $D G K K$ as the hypospadias susceptibility gene in the identified X-chromosomal locus as the LD block in which the gene is located encompasses only DGKK (Supplementary Fig. 2). Because the LD block also covers likely regulatory regions, variants regulating $D G K K$ expression may underlie the association of DGKK with hypospadias. We performed real-time quantitative PCR analyses showing that $D G K K$ is expressed in preputial skin of all investigated healthy boys $(n=10)$ and of hypospadias cases $(n=14)$ (Supplementary Fig. 3). Expression was lower in individuals with the A (risk) allele $(n=15)$ of rs1934179 ( $P=$ 0.047) (Fig. 1). These results suggest that variants regulating DGKK mRNA expression underlie the association of rs1934179 with hypospadias. A search for potential functional variants identified one SNP in a FOXL1 transcription factor binding site, rs1934176, which is in high LD $\left(r^{2}=0.99\right)$ with $r s 1934179 ;$ however, the significance of this SNP requires further study.

SNPs in GRID1, PPARGC1B and KIAA2022 showed associations in the same direction in the discovery sample and in both replication samples, resulting in outcomes with a higher level of statistical significance in the meta-analysis. This suggests that nonsignificance of results may be due to lack of power. Indeed, the power of our study to detect associations with $\mathrm{OR}<1.5$ was limited and was even further reduced by the fact that we used DNA pooling. Using DNA pools instead of individual DNA samples results in less accurate allele frequency estimates, possibly producing more false-positive and false-negative findings. Validating our results by individual 
genotyping enabled us to identify false-positive findings arising from such inaccurate estimates. False-negative results cannot be identified, however, and we may have missed additional associations that we would have detected with a GWAS based on individual genotyping. In addition, we may have missed associations with rare variants by excluding SNPs with MAF below $5 \%$, that is, SNPs for which we had insufficient power. Therefore, individual GWAS (preferentially in larger samples) may identify additional hypospadias loci.

Figure 1. Quantification of DGKK mRNA expression ( \pm s.e.m.) in preputial skin of hypospadias cases and controls relative to GAPDH mRNA expression.

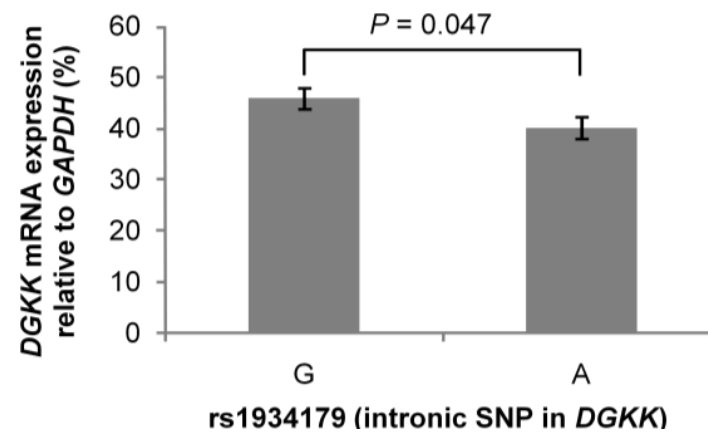

Previously performed studies showed familial occurrence of hypospadias for anterior and middle forms of hypospadias but not for posterior types ${ }^{1,19}$. Because of this apparent etiologic heterogeneity, we included only anterior and middle cases in the current analyses. As expected, an additional analysis of the SNPs in DGKK in cases with posterior hypospadias showed weaker associations (Table 3), although the small number of cases used may have hampered a fair comparison. Nevertheless, these data are compatible with anterior and middle forms of hypospadias having an oligogenic or polygenic multifactorial etiology, including a crucial role for $D G K K$, and with posterior forms having a different etiology. These results warrant stratification by hypospadias phenotype based on location of the urethral opening in future genetic studies, which may reduce genetic heterogeneity and improve the reproducibility of the results.

In summary, we have identified a new X-chromosomal risk locus for hypospadias. We showed expression of $D G K K$ in preputial skin, which was lower in boys with the risk allele. We propose $D G K K$ as a major risk gene for anterior and middle forms of hypospadias. Because hypospadias is a fusion defect, $D G K K$ might be important for other congenital closure defects as well. 
Table 3. Association of different forms of hypospadias with SNPs in DGKK.

\begin{tabular}{|c|c|c|c|c|c|}
\hline \multirow{2}{*}{$\begin{array}{l}\text { Study population } \\
\left(\mathrm{n}_{\text {controls }} / \mathrm{n}_{\text {cases }}\right)\end{array}$} & \multicolumn{2}{|c|}{ Minor allele (A) frequency (\%) } & \multirow[b]{2}{*}{ OR } & \multirow[b]{2}{*}{$(95 \% \mathrm{Cl})$} & \multirow[b]{2}{*}{$\chi^{2} P$} \\
\hline & Controls & Cases & & & \\
\hline \multicolumn{6}{|l|}{ rs1934179 in DGKK } \\
\hline \multicolumn{6}{|l|}{ Dutch sample } \\
\hline \multicolumn{6}{|l|}{ Anterior and middle cases (494/436) } \\
\hline (cases used in the discovery sample) & 32.9 & 54.6 & 2.46 & $(1.88-3.21)$ & $2.5 \times 10^{-11}$ \\
\hline Posterior cases (494/87) & 32.9 & 38.1 & 1.26 & $(0.78-2.03)$ & 0.348 \\
\hline \multicolumn{6}{|l|}{ Swedish sample } \\
\hline \multicolumn{6}{|l|}{ Anterior and middle cases $(402 / 266)$} \\
\hline Posterior cases (402/62) & 31.0 & 45.9 & 1.89 & $(1.09-3.26)$ & 0.021 \\
\hline \multicolumn{6}{|l|}{ rs7063116 near DGKK } \\
\hline \multicolumn{6}{|l|}{ Dutch sample } \\
\hline $\begin{array}{l}\text { Anterior and middle cases (494/436) } \\
\text { (cases used in the discovery sample) }\end{array}$ & 29.3 & 48.3 & 2.25 & $(1.72-2.96)$ & $2.9 \times 10^{-9}$ \\
\hline Posterior cases (494/87) & 29.3 & 26.2 & 0.86 & $(0.51-1.45)$ & 0.565 \\
\hline \multicolumn{6}{|l|}{ Swedish sample } \\
\hline $\begin{array}{l}\text { Anterior and middle cases }(402 / 266) \\
\text { (cases used in the replication sample) }\end{array}$ & \multicolumn{4}{|c|}{ Anterior and middle cases $(402 / 266)$} & $2.7 \times 10^{-6}$ \\
\hline Posterior cases $(402 / 62)$ & 29.4 & 41.0 & 1.67 & $(0.96-2.91)$ & 0.067 \\
\hline
\end{tabular}

OR, odds ratio; $\mathrm{Cl}$, confidence interval.

\section{Acknowledgements}

We thank all cases and parents for their cooperation in this study. We are grateful to the Microarray Facility Nijmegen of the Department of Human Genetics (RUNMC), in particular to M. Steehouwer, for performing the microarray experiments, and to T. Vrijenhoek and J. HehirKwa for their assistance in data analysis. We would also like to thank everyone involved in the data collection, S. van der Velde-Visser, C. Beumer, K. Kwak, J. Knoll, R. de Gier, B. Kortmann, A. Paauwen, H.G. Kho, J. Driessen and the anesthesiologists of OR 18. Finally, we are grateful to M. Coenen, J. Groothuismink, R. Makkinje and M. Schijven aars for their practical guidance. This research is performed within a PhD project supported by the Radboud University Nijmegen Medical Centre and with extra budget from the Urology Foundation 1973. J. Knight is funded by the Department of Health through the National Institute for Health Research (NIHR) comprehensive Biomedical Research Centre award to Guy's and St Thomas' NHS Foundation Trust in partnership with King's College London and King's College Hospital NHS Foundation Trust. 


\section{Author contributions}

L.F.M.v.d.Z. was the principal investigator who conducted the study. I.A.L.M.v.R., N.R., B.F. and N.V.A.M.K. designed the study and obtained financial support. L.F.M.v.d.Z., I.A.L.M.v.R., W.FJ.F., K.Y.R., E.M.H.F.B., S.H.H.M.V., L.A.L.M.K., N.R., B.F. and N.V.A.M.K. were involved in the collection of the discovery sample and the Dutch replication sample. J.A.V., A.A.-V. and B.F. collected the in-house controls. X.Z., E.M. and A.N. were responsible for the collection of the Swedish replication sample. L.Q. and L.S.B. collected the prepuce samples and performed the expression studies. L.F.M.v.d.Z. conducted all statistical analyses in collaboration with I.A.L.M.v.R., J.K. and A.R.T.D. L.F.M.v.d.Z. took primary responsibility for drafting the manuscript, with intellectual contributions, editing and approval from all other authors.

\section{References}

1. Fredell L, Kockum I, Hansson E, Holmner S, Lundquist L, Läckgren G, Pedersen J, Stenberg A, Westbacke $G$, Nordenskjöld A. Heredity of hypospadias and the significance of low birth weight. J Urol 2002:167;1423-1427.

2. Schnack TH, Zdravkovic S, Myrup C, Westergaard T, Christensen K, Wohlfahrt J, Melbye M. Familial aggregation of hypospadias: a cohort study. Am J Epidemiol 2007:167;251-256.

3. Watanabe M, Yoshida R, Ueoka K, Aoki K, Sasagawa I, Hasegawa T, Sueoka K, Kamatani N, Yoshimura Y, Ogata T. Haplotype analysis of the estrogen receptor 1 gene in male genital and reproductive abnormalities. Hum Reprod 2007:22;1279-1284.

4. Wang Y, Li Q, Xu J, Liu Q, Wang W, Lin Y, Ma F, Chen T, Li S, Shen Y. Mutation analysis of five candidate genes in Chinese patients with hypospadias. Eur J Hum Genet 2004:12;706-712.

5. Aschim EL, Nordenskjöld A, Giwercman A, Lundin KB, Ruhayel Y, Haugen TB, Grotmol T, Giwercman YL. Linkage between cryptorchidism, hypospadias, and GGN repeat length in the androgen receptor gene. J Clin Endocrinol Metab 2004:89;5105-5109.

6. Beleza-Meireles A, Omrani D, Kockum I, Frisén L, Lagerstedt K, Nordenskjöld A. Polymorphisms of estrogen receptor $\beta$ gene are associated with hypospadias. J Endocrinol Invest 2006:28;5-10.

7. Beleza-Meireles A, Töhönen V, Söderhäll C, Schwentner C, Radmayr C, Kockum I, Nordenskjöld A. Activating transcription factor 3: a hormone responsive gene in the etiology of hypospadias. Eur J Endocrinol 2008:158;729-739.

8. Radpour R, Rezaee M, Tavasoly A, Solati S, Saleki A. Association of long polyglycine tracts (GGN repeats) in exon 1 of the androgen receptor gene with cryptorchidism and penile hypospadias in iranian patients. J Androl 2007:28;164-169.

9. Beleza-Meireles A, Kockum I, Lundberg F, Söderhäll C, Nordenskjöld A. Risk factors for hypospadias in the estrogen receptor 2 gene. J Clin Endocrinol Metab 2007:92;3712-3718. 
10. Thai HTT, Kalbasi M, Lagerstedt K, Frisén L, Kockum I, Nordenskjöld A. The valine allele of the V89L polymorphism in the 5 - $\alpha$-reductase gene confers a reduced risk for hypospadias. $J$ Clin Endocrinol Metab 2005:90;6695-6698.

11. Ban S, Sata F, Kurahashi N, Kasai S, Moriya K, Kakizaki H, Nonomura K, Kishi R. Genetic polymorphisms of ESR1 and ESR2 that may influence estrogen activity and the risk of hypospadias. Hum Reprod 2008:23;1466-1471.

12. van der Zanden LFM, van Rooij IALM, Feitz WFJ, Vermeulen SHHM, Kiemeney LALM, Knoers NVAM, Roeleveld N, Franke B. Genetics of hypospadias: are single-nucleotide polymorphisms in SRD5A2, ESR1, ESR2, and ATF3 really associated with the malformation? J Clin Endocrinol Metab 2010:95;2384-2390.

13. Butcher LM, Davis OSP, Craig IW, Plomin R. Genome-wide quantitative trait locus association scan of general cognitive ability using pooled DNA and 500K single nucleotide polymorphism microarrays. Genes Brain Behav 2008:7;435-446.

14. Macgregor S, Zhao ZZ, Henders A, Nocholas MG, Montgomery GW, Visscher PM. Highly costefficient genome-wide association studies using DNA pools and dense SNP arrays. Nucleic Acids Res 2008:36;e35.

15. Pearson JV, Huentelman MJ, Halperin RF, Tembe WD, Melquist S, Homer N, Brun $M$, Szelinger S, Coon KD, Zismann VL et al. Identification of the genetic basis for complex disorders by use of pooling-based genomewide single-nucleotide-polymorphism association studies. Am J Hum Genet 2007:80;126-139.

16. Shifman S, Bhomra A, Smiley S, Wray NR, James MR, Martin NG, Hettema JM, An SS, Neale MC, van den Oord EJCG et al. A whole genome association study of neuroticism using DNA pooling. Mol Psychiatry 2008:13;302-312.

17. Lambert JC, Heath S, Even G, Campion D, Sleegers K, Hiltunen M, Combarros O, Zelenika D, Bullido MJ, Tavernier B et al. Genome-wide association study identifies variants at CLU and CR1 associated with Alzheimer's disease. Nat Genet 2009:41;1094-1099.

18. Imai S, Kai M, Yasuda S, Kanoh H, Sakane F. Identification and characterization of a novel human type II diacylglycerol kinase, DGK kappa. J Biol Chem 2005:280;39870-39881.

19. Brouwers MM, van der Zanden LFM, de Gier RPE, Barten EJ, Zielhuis GA, Feitz WFJ, Roeleveld N. Hypospadias: risk factor patterns and different phenotypes. BJU Int 2010:105;254-262.

\section{URLS}

http://www.eurocat-network.eu/; R, http://www.R-project.org; Review Manager 5, http://www.ccims.net/revman. 


\section{Online methods}

\section{Pool construction}

The AGORA (Aetiologic research into Genetic and Occupational/environmental Risk factors for Anomalies in children) project of the Radboud University Nijmegen Medical Centre (RUNMC), Nijmegen, The Netherlands, is building a data bank and bio bank with questionnaire data and DNA samples from individuals with a congenital malformation or childhood cancer, as well as their parents. DNA was available for 679 hypospadias cases from the AGORA project (Supplementary Fig. 1 and Supplementary Table 1) and 596 unaffected male controls of European descent from the Nijmegen Biomedical Study ${ }^{20}$. The Arnhem-Nijmegen Regional Committee on Research Involving Human Subjects approved both studies. All participants and/or their parents gave written informed consent for participation in the studies. A detailed description of the study populations and pooling process can be found in the Supplementary Note. Finally, DNA samples of 436 cases of European descent with isolated anterior or middle hypospadias and 494 unaffected male controls of European descent were pooled in eight case pools and eight control pools.

\section{Genome-wide analysis}

We allelotyped each pool in duplicate using Affymetrix GeneChip 6.0 microarrays containing 906,600 polymorphic SNPs. Array experiments were performed according to protocols provided by the manufacturer. We used the SNPMaP package ${ }^{21}$ in the statistical software program $\mathrm{R}$ (see URLs) to calculate relative allele signal (RAS) scores and k-corrected raw allele frequency $\left(R A F_{k}\right)$ estimates for each SNP, as is described in the Supplementary Note.

A total of 574,400 SNPs passed quality control steps (described in the Supplementary Note) and were included in the association analyses. We averaged data across case pools and control pools separately to obtain $R A F_{k}$ and $R A S$ estimates for cases and controls. We subsequently calculated the modified $\chi^{2}$ statistic ${ }^{16}$, which is expressed as:

$$
Z=\frac{P_{\text {cases }}-P_{\text {controls }}}{\sqrt{P_{p} \times\left(1-P_{p}\right) \times\left(1 / 2 N_{\text {cases }}+1 / 2 N_{\text {controls }}\right)+\sigma_{\text {pool }}^{2} \times\left(1 / n p_{\text {cases }}+1 / n p_{\text {controls }}\right)}}
$$

Where $P_{\text {cases }}$ is the allele frequency estimate $\left(R A F_{k}\right)$ in the case pools, $P_{\text {controls }}$ is the $R A F_{k}$ in the control pools and $P_{p}$ is an estimate of the allele frequency in the population, for which we used the allele frequency in 603 individually genotyped in-house controls of European descent ${ }^{22}$. $N_{\text {cases }}$ is the number of individuals in the case pools and $N_{\text {controls }}$ is the number of individuals in the control pools, taking into account the loss of cases and controls after the quality control. A SNP-specific variance calculated across the two measurements for each DNA pool was averaged across the pools to obtain $\sigma_{\text {pool }}^{2}$. Finally, $n p_{\text {cases }}$ and $n p_{\text {controls }}$ are the number of 
measurements (pools) for the case and control pools. We selected the 5,000 SNPs with the highest $Z$ scores, and calculated two additional statistics for these SNPs: the standard $\chi^{2}$ statistic using the expected numbers of alleles in the cases and controls calculated from the $R A F_{k}$ estimates and the adjusted $\chi^{2}$ statistic using the RAS values. Combining the results from all three statistics enabled us to select the most promising SNPs.

We used several criteria to select SNPs from the pooled GWAS as eligible for individual genotyping in the discovery sample to validate the results as is described in the Supplementary Note. Ultimately, 20 SNPs were eligible. As seven of these 20 SNPs were SNPs in high LD within DGKK (Supplementary Fig. 2), we genotyped the SNP that tagged most of the other SNPS (rs1934179, an intronic SNP). In addition, we genotyped a potentially regulatory SNP in the $5^{\prime}$ upstream region (rs7063116).

\section{Validation of the results from the pooled GWAS}

Taqman SNP genotyping assays could not be designed for four of the 15 SNPs that were selected for individual genotyping in the discovery sample. We excluded these SNPs from further analysis. The other 11 SNPs (Supplementary Table 3) were individually genotyped using 5' nuclease TaqMan SNP genotyping assays (Supplementary Table 8). In each 96-well plate, we loaded five wells with randomly selected duplicate DNA samples from the same and other plates for quality control purposes. In addition, we included four blanks in each plate. Genotyping was completed with a success rate of at least $99 \%$.

All genotype frequencies in controls were in Hardy-Weinberg equilibrium, with $P$ values ranging from 0.34 to 0.94 . For the genotyped SNPs, we calculated ORs for hypospadias risk and the corresponding 95\% confidence intervals (Cls) at a genotypic and an allelic level using the most frequent homozygous genotypes in controls as reference values. Furthermore, we performed $\chi^{2}$ tests. When the expected cell numbers were below five, exact $95 \% \mathrm{Cls}$ around the ORs were calculated using the Fisher exact method. Ten of the associations were statistically significant $(P<0.05)$, but only the association with the two SNPs in the Xchromosomal DGKK gene reached genome-wide significance $\left(P<5.0 \times 10^{-8}\right)$ (Supplementary Table 4). These results were validated by genotyping the parents of the cases. For these caseparent triads, we used the transmission disequilibrium test (TDT) ${ }^{23}$ for statistical analysis of the data with the software program Haploview 4.1 (ref.24). Furthermore, we calculated the ORs for hypospadias risk and corresponding $95 \% \mathrm{Cls}$ at the allelic level ${ }^{25}$ (Table 2).

\section{Replication studies}

A detailed description of the study populations can be found in the Supplementary Note. The Arnhem-Nijmegen Regional Committee on Research Involving Human Subjects and the Ethics Committee at Karolinska Institutet approved the studies and all participants and/or their parents gave written informed consent for participation in the studies. 
For the Dutch replication sample, we genotyped 133 cases of European descent with isolated anterior or middle hypospadias and their parents for the SNPs that were associated with hypospadias in the individually genotyped discovery sample $(P<0.05)$. Genotyping was completed with a success rate of at least $95 \%$. All genotype frequencies in the parents were in Hardy-Weinberg equilibrium (with $P$ values ranging from 0.16 to 0.99 ). For these case-parent triads, we again used the $\mathrm{TDT}^{23}$ for statistical analysis of the data with the software program Haploview 4.1 (ref.24), and we calculated the ORs for hypospadias risk and the corresponding $95 \% \mathrm{Cls}$ at the allelic level ${ }^{25}$ (Supplementary Table 5).

For the Swedish replication sample, we genotyped 266 Swedish cases with anterior or middle hypospadias and 402 male Swedish controls for the SNPs that were associated with hypospadias in the individually genotyped discovery sample $(P<0.05)$. Genotyping was completed with a success rate of at least $98 \%$. All genotype frequencies in the controls were in Hardy-Weinberg equilibrium (with $P$ values ranging from 0.13 to 0.99 ), except for rs1022357 in SLCO3A1 $(P=0.01)$. However, after correcting the critical $P$ value for multiple testing, this result did not reach statistical significance (critical Bonferroni $P<0.005$ ). We calculated ORs for hypospadias risk and the corresponding $95 \% \mathrm{Cls}$ at genotypic and allelic level, performed $\chi^{2}$ tests and calculated exact $95 \% \mathrm{Cls}$ around the ORs using the Fisher exact method when expected cell numbers were below five (Supplementary Table 6).

\section{Meta-analysis}

We combined the results of both the discovery sample and the two replication samples in a meta-analysis in Review Manager 5 (see URLS) using the inverse-variance method and random effects models (Supplementary Table 7).

\section{Expression of DGKK}

We isolated RNA from preputial skin samples from 14 hypospadias cases and ten age-matched controls. The origin of the samples and the methods used are described in the Supplementary Note. We performed RT-PCR according to the standard protocol as described in the Supplementary Note. Expression levels of DGKK were reported relative to GAPDH. We also genotyped DNA samples for the two SNPs in DGKK and compared relative gene expression levels between boys with the $\mathrm{G}$ allele $(45.9 \%$ of $G A P D H, \mathrm{n}=9)$ and the $\mathrm{A}$ (risk) allele $(40.1 \%$ of GAPDH, $\mathrm{n}=15$ ) of the X-chromosomal SNP rs1934179 in DGKK using the independent samples $t$ test.

\section{Search for potential functional variants}

We searched different databases, such as dbSNP and HapMap, for nonsynonymous SNPs that might be causative variants, taking validation of the SNPs, conservation of amino acids, and Grantham scores of amino acid replacements into account. Concerning non-coding areas, we 
used the UCSC genome browser to check for microRNA binding sites, enrichments of histone marks associated with enhancers or promoters, and for transcription factor binding sites.

\section{Calculation of Population Attributable Fraction}

We calculated the population attributable fraction $(P A F) \mathrm{as}^{26}$ :

$$
P A F=\frac{q(O R-1)}{q(O R-1)+1}
$$

where $\mathrm{OR}$ is the odds ratio and $q$ is the proportion of exposed individuals (proportion of individuals with the risk allele) in the control group, which is the A allele of rs1934179 in DGKK.

\section{References}

20. Hoogendoorn EH, Hermus AR, de Vegt F, Ross HA, Verbeek ALM, Kiemeney LALM, Swinkels DW, Sweep FCGJ, den Heijer M. Thyroid function and prevalence of anti-thyroperoxidase antibodies in a population with borderline sufficient iodine intake: influences of age and sex. Clin Chem 2006:52;104-111.

21. Davis OSP, Plomin R, Schalkwyk LC. The SNPMaP package for R: a framework for genomewide association using DNA pooling on microarrays. Bioinformatics 2009:25;281-283.

22. Franke B, Arias Vasquez A, Veltman JA, Brunner HG, Rijpkema M, Fernández G. Genetic variation in CACNA1C, a gene associated with bipolar disorder, influences brainstem rather than gray matter volume in healthy individuals. Biol Psychiat 2010:68;586-588.

23. Spielman RS, McGinnis RE, Ewens WJ. Transmission test for linkage disequilibrium: the insulin gene region and insulin-dependent diabetes mellitus (IDDM). Am J Hum Genet 1993:52;506516.

24. Barrett JC, Fry B, Maller J, Daly MJ. Haploview: analysis and visualization of LD and haplotype maps. Bioinformatics 2005:21;263-265.

25. Kazeem GR, Farrall M. Integrating case-control and TDT studies. Ann Hum Genet 2005:69; 329-335.

26. Rothman KJ, Greenland S, Lash TL. Modern epidemiology. (Lippincott Williams \& Wilkins, Philadelphia, 2008). 


\section{Supplementary material}

Supplementary figures

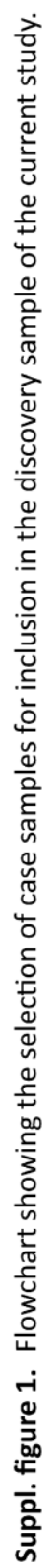

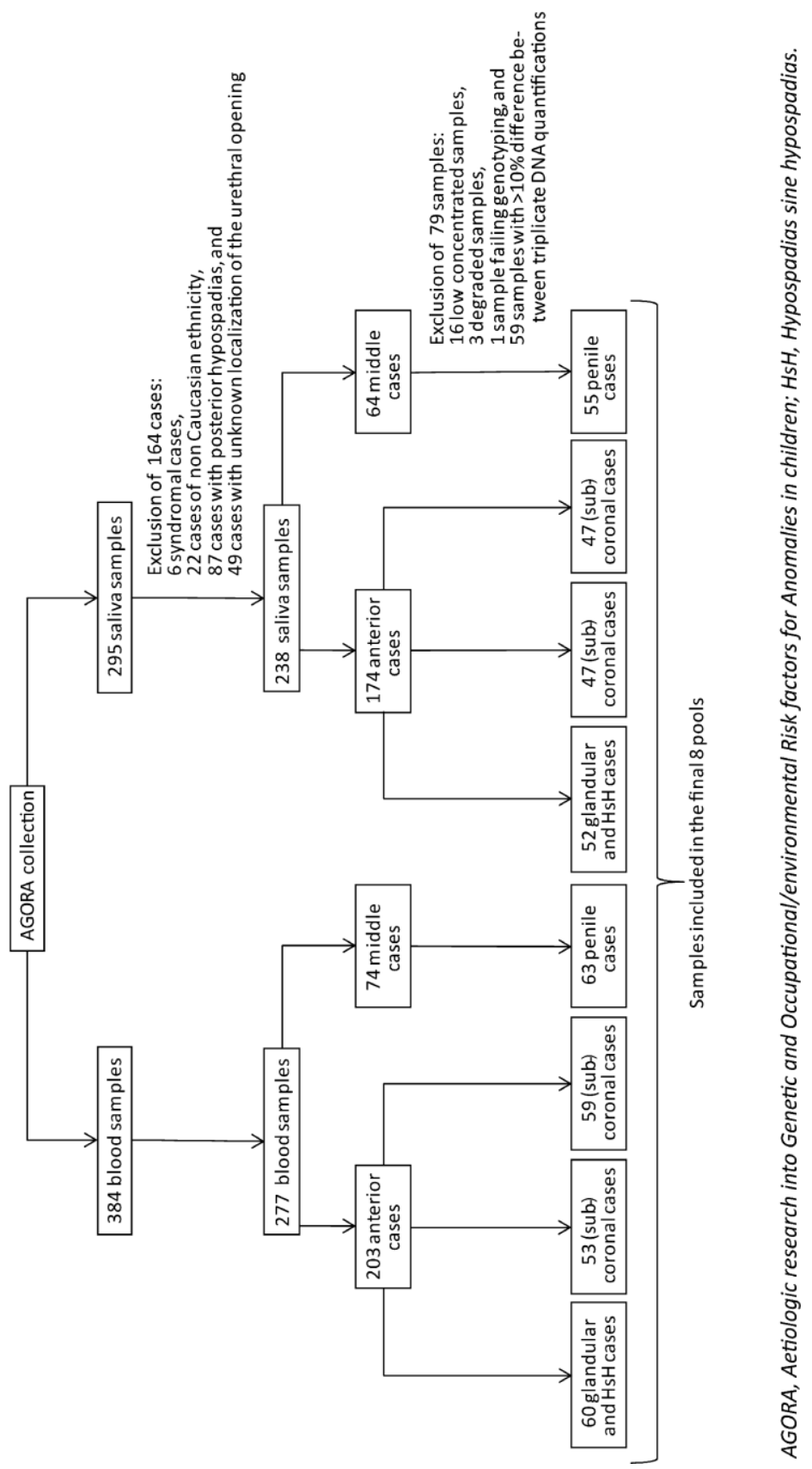




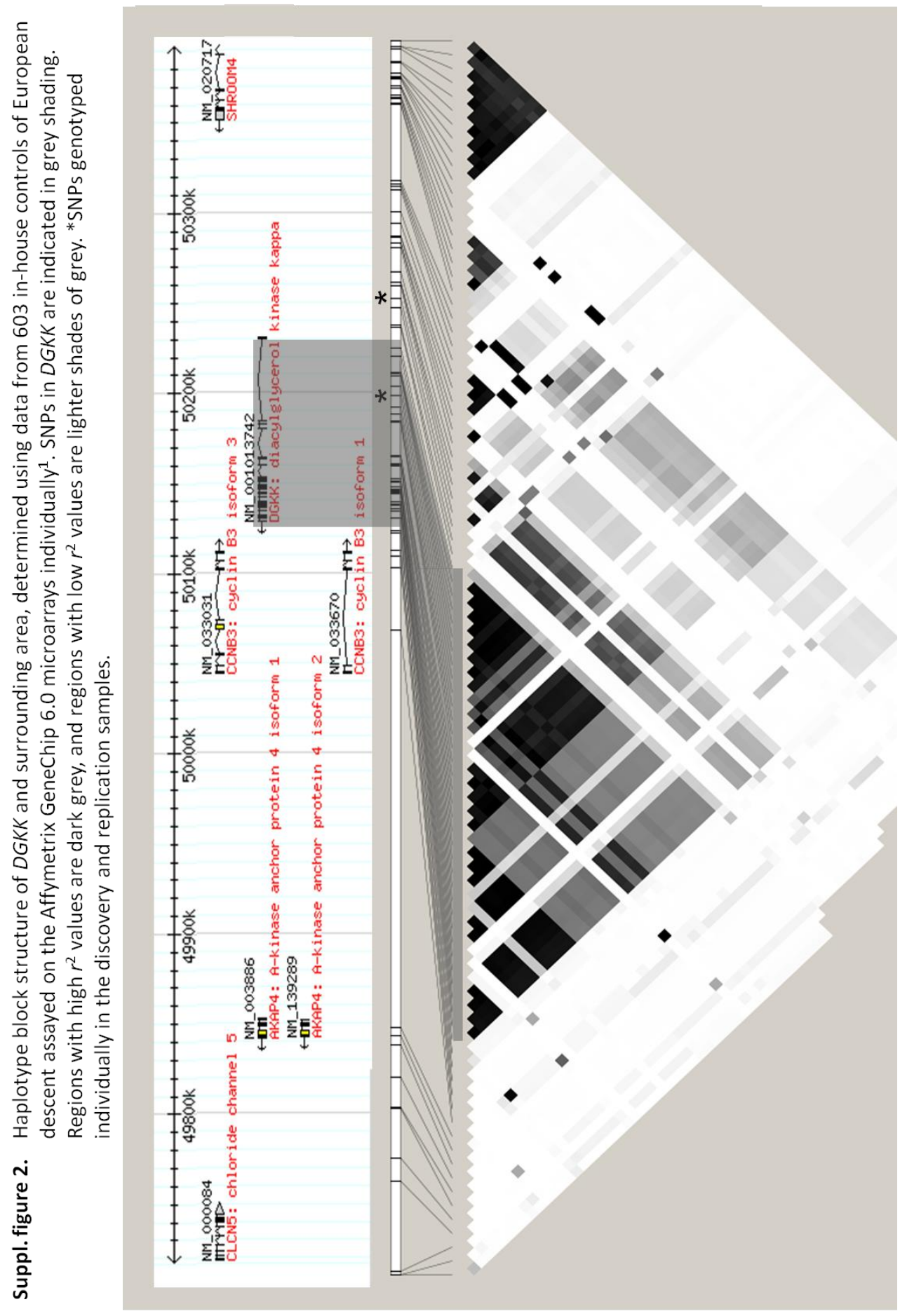


Suppl. figure 3. Quantification of DGKK mRNA expression ( \pm s.e.m.) in preputial skin of hypospadias cases and controls relative to GAPDH mRNA expression. Relative gene expression levels were compared between cases $(43.1 \%$ of GAPDH, $\mathrm{n}=14)$ and controls $(41.2 \%$ of $G A P D H, \mathrm{n}=10)$ using the independent samples t-test.

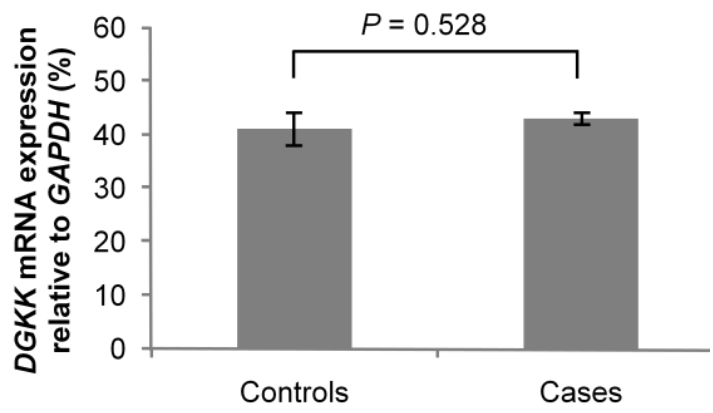

\section{Supplementary tables}

Suppl. table 1. Clinical characteristics of the hypospadias patients in the discovery sample.

\begin{tabular}{|c|c|c|c|c|c|c|}
\hline & \multicolumn{6}{|c|}{ Anatomical location of urethral opening } \\
\hline & \multicolumn{3}{|c|}{ Anterior $n=318$ (73\%) } & \multicolumn{3}{|c|}{ Middle $n=118$ (27\%) } \\
\hline & $\mathrm{HsH}$ & Glandular & $\begin{array}{l}\text { (Sub)- } \\
\text { coronal }\end{array}$ & $\begin{array}{l}\text { Distal } \\
\text { penile }\end{array}$ & Midshaft & $\begin{array}{l}\text { Proximal } \\
\text { penile }\end{array}$ \\
\hline Total & 33 & 88 & 197 & 63 & 48 & 7 \\
\hline Chordee & $21(64 \%)$ & $30(34 \%)$ & $115(58 \%)$ & $41(65 \%)$ & 38 (79\%) & $6(86 \%)$ \\
\hline Cryptorchidism $^{a}$ & $4(12 \%)$ & $2(2 \%)$ & $11(6 \%)$ & $3(5 \%)$ & $1(2 \%)$ & 0 \\
\hline Other deformities ${ }^{b}$ & $4(12 \%)$ & $10(11 \%)$ & $8(4 \%)$ & $4 \quad(6 \%)$ & 0 & 0 \\
\hline
\end{tabular}

$\mathrm{HsH}$, Hypospadias sine hypospadias; ${ }^{a}$ including only cases that underwent orchidopexy or orchidectomy; ${ }^{b}$ including cases with heart-, renal- and gastro-intestinal deformities, neural tube defects, cleft lip and/or palate and deformities of the lower extremities.

Suppl. table 2. SNPs appearing in the top 200 ranks for all three statistical tests used. The grey-shaded SNPs are the SNPs that were selected based on the criteria used. As seven of these 20 SNPs were SNPs in high LD within the DGKK gene, we selected the SNP that tagged most of the other SNPs (rs1934179) for individual genotyping in the discovery sample. In addition, we genotyped a potentially regulatory SNP in the $5^{\prime}$-upstream region (rs7063116). Taqman SNP genotyping assays could not be designed for four of the fifteen SNPs that were thus selected for individual genotyping in the discovery sample. 
Suppl. table 2.

\begin{tabular}{|c|c|c|c|c|c|c|c|c|c|}
\hline SNP & Chr & $\begin{array}{c}\text { Rank } \\
\text { adj } \\
\chi^{2} \text {-test } \\
\text { using } \\
\text { RAS }\end{array}$ & $\begin{array}{c}\text { Rank } \\
\text { adj } \\
\chi^{2} \text {-test } \\
\text { using } \\
\text { RAF }_{k}\end{array}$ & $\begin{array}{c}\text { Rank } \\
\chi^{2} \text {-test } \\
\text { using } \\
\text { RAF }_{k}\end{array}$ & Nearest gene & Location & $\begin{array}{l}\text { MAF in } \\
\text { in- } \\
\text { house } \\
\text { control } \\
\text { samples }\end{array}$ & $\begin{array}{l}\text { Sup- } \\
\text { porting } \\
\text { evidence } \\
\text { from } \\
\text { SNPs in } \\
\text { LD }^{\mathrm{a}}\end{array}$ & $\begin{array}{c}\text { Reason } \\
\text { exclusion } \\
\text { from } \\
\text { individual } \\
\text { geno- } \\
\text { typing }\end{array}$ \\
\hline rs1934179 & $x$ & 46 & 21 & 4 & $D G K K$ & intron & 0.337 & yes & \\
\hline rs16985967 & 22 & 26 & 4 & 12 & TTC28 & intron & 0.080 & yes & \\
\hline rs7085066 & 10 & 35 & 19 & 31 & SLC16A12 & intron & 0.105 & yes & \\
\hline rs1022357 & 15 & 199 & 176 & 79 & SLCO3A1 & intron & 0.166 & yes & \\
\hline rs10184015 & 2 & 32 & 17 & 83 & SOS1 & intron & 0.066 & yes & \\
\hline rs6607499 & $x$ & 38 & 33 & 133 & KIAA2022 & $12 \mathrm{~kb}$ up & 0.065 & yes & \\
\hline rs4705372 & 5 & 165 & 119 & 168 & PPARGC1B & intron & 0.123 & yes & \\
\hline rs3755071 & 2 & 31 & 81 & 16 & SRBD1 & intron & 0.226 & - & \\
\hline rs1880386 & 10 & 180 & 42 & 35 & GRID1 & intron & 0.152 & - & \\
\hline rs12660161 & 6 & 30 & 11 & 56 & MTHFD1L & $39 \mathrm{~kb}$ down & 0.085 & - & \\
\hline rs 7896487 & 10 & 19 & 144 & 55 & $\mathrm{CDH} 23$ & intron & 0.123 & - & assay \\
\hline rs9735061 & 11 & 73 & 186 & 139 & FAM86A & $43 \mathrm{~kb}$ up & 0.122 & - & assay \\
\hline rs7321040 & 13 & 21 & 13 & 75 & DIAPH3 & $31 \mathrm{~kb}$ down & 0.055 & - & assay \\
\hline rs10997978 & 10 & 28 & 2 & 26 & MYPN & intron & 0.056 & yes & assay \\
\hline rs1934171 & $x$ & 3 & 1 & 1 & $D G K K$ & intron & 0.336 & yes & other SNP \\
\hline rs1934188 & $x$ & 52 & 5 & 2 & $D G K K$ & intron & 0.314 & yes & other SNP \\
\hline rs1934176 & $x$ & 8 & 3 & 3 & $D G K K$ & intron & 0.337 & yes & other SNP \\
\hline$r s 4826629$ & $x$ & 99 & 79 & 5 & $D G K K$ & intron & 0.316 & yes & other SNP \\
\hline rs1934175 & $x$ & 77 & 57 & 8 & $D G K K$ & intron & 0.336 & yes & other SNP \\
\hline rs17281440 & $x$ & 182 & 169 & 34 & $D G K K$ & intron & 0.240 & yes & other SNP \\
\hline rs17051831 & 13 & 85 & 95 & 118 & $N B E A$ & intron & 0.096 & - & LD/MAF \\
\hline rs7229296 & 18 & 126 & 103 & 137 & $R A B 31$ & 9 kb down & 0.092 & - & $\mathrm{LD} / \mathrm{MAF}$ \\
\hline rs4869674 & 5 & 13 & 27 & 32 & SPEF2 & intron & 0.091 & - & LD/MAF \\
\hline rs17126762 & 1 & 34 & 14 & 80 & $C A C H D 1$ & intron & 0.072 & - & $\mathrm{LD} / \mathrm{MAF}$ \\
\hline rs17021660 & 4 & 16 & 9 & 22 & POU4F2 & 17 kb up & 0.062 & - & $\mathrm{LD} / \mathrm{MAF}$ \\
\hline rs527834 & 15 & 193 & 18 & 13 & CHRM /AVEN & intron & 0.053 & - & LD/MAF \\
\hline rs16841107 & 1 & 196 & 88 & 69 & RGS7 & intron & 0.050 & - & $\mathrm{LD} / \mathrm{MAF}$ \\
\hline rs12465925 & 2 & 191 & 151 & 72 & TMEFF2 & intron & 0.132 & no & LD \\
\hline rs17236770 & 15 & 135 & 106 & 21 & TMEM85 & intron & 0.123 & no & LD \\
\hline rs3771698 & 2 & 9 & 32 & 17 & $B A Z 2 B$ & intron & 0.088 & no & LD \\
\hline rs16842909 & 2 & 83 & 50 & 97 & MAP2 & intron & 0.072 & no & LD \\
\hline rs 764125 & 3 & 78 & 40 & 146 & CMTM8 & intron & 0.057 & no & LD \\
\hline rs9308056 & 4 & 6 & 93 & 172 & TKTL2 & $54 \mathrm{~kb}$ down & 0.083 & yes & distance \\
\hline rs2114929 & 5 & 48 & 102 & 62 & TARS & 63 kb up & 0.141 & yes & distance \\
\hline rs1560398 & 18 & 10 & 8 & 40 & $M C 4 R$ & $123 \mathrm{~kb}$ up & 0.063 & - & distance \\
\hline rs1397151 & 16 & 79 & 39 & 76 & CES7 & $130 \mathrm{~kb}$ up & 0.057 & yes & distance \\
\hline rs16888346 & 4 & 63 & 38 & 18 & HSP9OAB2P & $135 \mathrm{~kb}$ up & 0.113 & - & distance \\
\hline rs6847625 & 4 & 5 & 10 & 52 & GPRIN3 & 197 kb up & 0.069 & - & distance \\
\hline rs10497759 & 2 & 81 & 72 & 6 & SLC39A10 & $244 \mathrm{~kb}$ up & 0.297 & - & distance \\
\hline rs2174232 & 10 & 53 & 37 & 67 & ZWINT & $816 \mathrm{~kb}$ up & 0.070 & - & distance \\
\hline
\end{tabular}


Suppl. table 2. (continued)

\begin{tabular}{|c|c|c|c|c|c|c|c|c|c|}
\hline SNP & Chr & $\begin{array}{c}\text { Rank } \\
\text { adj } \\
\chi^{2} \text {-test } \\
\text { using } \\
\text { RAS }\end{array}$ & $\begin{array}{c}\text { Rank } \\
\text { adj } \\
\chi^{2} \text {-test } \\
\text { using } \\
\text { RAF }_{k}\end{array}$ & $\begin{array}{c}\text { Rank } \\
\chi^{2} \text {-test } \\
\text { using } \\
\text { RAF }_{k}\end{array}$ & Nearest gene & Location & $\begin{array}{l}\text { MAF in } \\
\text { in- } \\
\text { house } \\
\text { control } \\
\text { samples }\end{array}$ & $\begin{array}{l}\text { Sup- } \\
\text { porting } \\
\text { evidence } \\
\text { from } \\
\text { SNPs in } \\
\text { LD }^{\mathrm{a}}\end{array}$ & $\begin{array}{l}\text { Reason } \\
\text { exclusion } \\
\text { from } \\
\text { individual } \\
\text { geno- } \\
\text { typing }\end{array}$ \\
\hline rs6127262 & 20 & 101 & 185 & 100 & DOK5 & $62 \mathrm{~kb}$ down & 0.010 & - & distance \\
\hline rs4850833 & 2 & 98 & 69 & 64 & PLCL1 & $73 \mathrm{~kb}$ down & 0.114 & yes & distance \\
\hline rs12544855 & 8 & 86 & 45 & 70 & LOC100129963 & $87 \mathrm{~kb}$ down & 0.100 & - & distance \\
\hline rs16864680 & 2 & 4 & 23 & 164 & LOC400940 & $91 \mathrm{~kb}$ down & 0.080 & - & distance \\
\hline rs10733948 & 10 & 176 & 107 & 142 & ZWINT & $131 \mathrm{~kb}$ down & 0.095 & no & distance \\
\hline$r s 2468265$ & 12 & 177 & 110 & 7 & SUDS3 & $199 \mathrm{~kb}$ down & 0.477 & - & distance \\
\hline rs10024666 & 4 & 57 & 35 & 175 & TRAM1L1 & $314 \mathrm{~kb}$ down & 0.078 & - & distance \\
\hline rs12265647 & 10 & 17 & 16 & 182 & YWHAZ & $321 \mathrm{~kb}$ down & 0.070 & - & distance \\
\hline rs11046765 & 12 & 1 & 6 & 33 & ETNK1 & $356 \mathrm{~kb}$ down & 0.061 & yes & distance \\
\hline rs5942497 & $x$ & 120 & 104 & 157 & CPXCR1 & $574 \mathrm{~kb}$ down & 0.063 & no & distance \\
\hline
\end{tabular}

Chr, chromosome; adj, adjusted; $R A S$, relative allele signal; $R A F_{k}$, $k$-corrected raw allele frequency estimate; $M A F$, minor allele frequency; $L D$, linkage disequilibrium; $k b$, kilobases; up, upstream; down, downstream; assay, assay unavailable; other SNP, other SNP in gene; $L D / M A F, L D$ and $M A F<0.10$; distance, gene distance; ${ }^{a}$ yes = supporting evidence defined as at least half of the SNPs in high $L D\left(r^{2}\right.$ $>0.8)$ having a low average $P$-value $\left(<0.22\right.$, the $10^{\text {th }}$ percentile of the average $P$-values of all 574,400 SNPS), no = reduced evidence defined as at least half of the SNPs in high LD having a high average $P$ value, - = no SNPs in high LD.

Suppl. table 3. Single nucleotide polymorphisms individually genotyped in the discovery sample.

\begin{tabular}{|c|c|c|c|}
\hline SNP & Chr & Nearest gene & Location \\
\hline rs1934179 & $\mathrm{x}$ & $D G K K$ & intron \\
\hline rs7063116 & $x$ & $D G K K$ & $21 \mathrm{~kb}$ upstream \\
\hline rs1880386 & 10 & GRID1 & intron \\
\hline rs6607499 & $x$ & KIAA2022 & $12 \mathrm{~kb}$ upstream \\
\hline rs12660161 & 6 & MTHFD1L & $39 \mathrm{~kb}$ downstream \\
\hline rs4705372 & 5 & PPARGC1B & intron \\
\hline rs7085066 & 10 & SLC16A12 & intron \\
\hline rs1022357 & 15 & SLCO3A1 & intron \\
\hline rs10184015 & 2 & sos1 & intron \\
\hline rs3755071 & 2 & SRBD1 & intron \\
\hline rs16985967 & 22 & TTC28 & intron \\
\hline
\end{tabular}

Chr, chromosome. 
Suppl. table 4. Association analyses with hypospadias for single nucleotide polymorphisms in selected genes in the discovery sample.

\begin{tabular}{|c|c|c|c|c|c|c|c|c|}
\hline $\begin{array}{c}\text { Controls } \\
n=494 \\
n(\%)\end{array}$ & $\begin{array}{r}\text { Cases } \\
n=436 \\
n(\%)\end{array}$ & OR (95\% Cl) & $\chi^{2} P$ & & $\begin{array}{c}\begin{array}{c}\text { Controls } \\
n=494 \\
n(\%)\end{array}\end{array}$ & $\begin{array}{r}\text { Cases } \\
n=436 \\
n(\%)\end{array}$ & OR (95\% C) & $\chi^{2} P$ \\
\hline \multicolumn{4}{|c|}{ Allele frequencies } & \multicolumn{5}{|c|}{ Genotype frequencies } \\
\hline \multicolumn{4}{|c|}{ rs1934179 in DGKK } & & & & & \\
\hline G $331(67)$ & $196(45)$ & 1.00 (ref) & ref & \multirow{2}{*}{\multicolumn{5}{|c|}{ Not applicable, X-chromosomal SNP }} \\
\hline A $162(33)$ & $236(55)$ & $2.46(1.88-3.21)$ & $2.5 \times 10^{-11}$ & & & & & \\
\hline \multicolumn{4}{|c|}{ rs7063116 near DGKK } & & & & & \\
\hline G $348(71)$ & $224(52)$ & 1.00 (ref) & ref & \multirow{2}{*}{\multicolumn{5}{|c|}{ Not applicable, X-chromosomal SNP }} \\
\hline A 144 (29) & $209(48)$ & $2.25(1.72-2.96)$ & $2.9 \times 10^{-9}$ & & & & & \\
\hline \multicolumn{9}{|c|}{ rs1880386 in GRID1 } \\
\hline C $844(86)$ & $698(81)$ & 1.00 (ref) & ref & CC & $360(73)$ & $285(66)$ & 1.00 (ref) & ref \\
\hline$T 140$ (14) & 162 (19) & $1.40(1.09-1.79)$ & 0.008 & CT & $124(25)$ & $128(30)$ & $1.30(0.97-1.75)$ & 0.075 \\
\hline & & & & $\pi$ & $8(2)$ & 17 (4) & $2.68(1.14-6.31)$ & 0.019 \\
\hline \multicolumn{4}{|c|}{ rs6607499 near KIAA2022 } & & & & & \\
\hline G $474(96)$ & $402(93)$ & 1.00 (ref) & ref & \multicolumn{5}{|c|}{ Not applicable, X-chromosomal SNP } \\
\hline A 18 (4) & 31 (7) & $2.03(1.12-3.68)$ & 0.018 & & & & & \\
\hline \multicolumn{9}{|c|}{ rs12660161 near MTHFD1L } \\
\hline$G 909(92)$ & $766(88)$ & 1.00 (ref) & ref & GG & $419(85)$ & $343(79)$ & 1.00 (ref) & ref \\
\hline$A \quad 79$ (8) & $100(12)$ & $1.50(1.10-2.05)$ & 0.010 & $A G$ & $71(14)$ & $80(18)$ & $1.38(0.97-1.95)$ & 0.073 \\
\hline & & & & $A A$ & $4(1)$ & $10(2)$ & $3.05(0.95-9.82)$ & 0.049 \\
\hline \multicolumn{4}{|c|}{ rs 4705372 in PPARGC1B } & & & & & \\
\hline G $856(87)$ & $714(82)$ & 1.00 (ref) & ref & GG & $371(75)$ & $298(69)$ & 1.00 (ref) & ref \\
\hline A $132(13)$ & $154(18)$ & $1.40(1.09-1.80)$ & 0.009 & $A G$ & $114(23)$ & $118(27)$ & $1.29(0.96-1.74)$ & 0.096 \\
\hline & & & & $A A$ & $9(2)$ & $18(4)$ & $2.49(1.10-5.62)$ & 0.024 \\
\hline \multicolumn{4}{|c|}{ rs7085066 in SLC16A12 } & & & & & \\
\hline G 898 (91) & $769(89)$ & 1.00 (ref) & ref & GG & $409(83)$ & $338(78)$ & 1.00 (ref) & ref \\
\hline C $90 \quad(9)$ & $95(11)$ & $1.23(0.91-1.67)$ & 0.177 & $C G$ & $80(16)$ & $93(22)$ & $1.41(1.01-1.96)$ & 0.043 \\
\hline & & & & CC & $5(1)$ & $1(0)$ & $0.24(0.01-2.18)^{\mathrm{a}}$ & 0.325 \\
\hline \multicolumn{4}{|c|}{ rs1022357 in SLCO3A1 } & & & & & \\
\hline A $824(84)$ & $689(79)$ & 1.00 (ref) & ref & $A A$ & $344(70)$ & $277(64)$ & 1.00 (ref) & ref \\
\hline G $162(16)$ & $179(21)$ & $1.32(1.04-1.67)$ & 0.020 & $A G$ & $136(28)$ & $135(31)$ & $1.23(0.93-1.64)$ & 0.151 \\
\hline & & & & GG & $13(3)$ & $22(5)$ & $2.10(1.04-4.25)$ & 0.035 \\
\hline \multicolumn{4}{|c|}{ rs10184015 in SOS1 } & & & & & \\
\hline G 923 (93) & $781(90)$ & 1.00 (ref) & ref & GG & $430(87)$ & $353(81)$ & 1.00 (ref) & ref \\
\hline$A \quad 65$ (7) & $87(10)$ & $1.58(1.13-2.21)$ & 0.007 & $A G$ & $63(13)$ & 75 (17) & 1.45 (1.01-2.09) & 0.044 \\
\hline & & & & $A A$ & $1(0)$ & $6(1)$ & $7.31(0.88-337)^{a}$ & 0.074 \\
\hline \multicolumn{4}{|c|}{ rs3755071 in SRBD1 } & & & & & \\
\hline A 690 (70) & $652(75)$ & 1.00 (ref) & ref & $A A$ & $238(48)$ & $242(56)$ & 1.00 (ref) & ref \\
\hline G $292(30)$ & $214(25)$ & $0.78(0.63-0.95)$ & 0.016 & $A G$ & $214(44)$ & 168 (39) & $0.77(0.59-1.01)$ & 0.060 \\
\hline & & & & GG & $39(8)$ & $23(5)$ & $0.58(0.34-1.00)$ & 0.049 \\
\hline \multicolumn{4}{|c|}{ rs16985967 in TTC28 } & & & & & \\
\hline C 924 (94) & $771(89)$ & 1.00 (ref) & ref & $C C$ & $432(88)$ & $339(78)$ & 1.00 (ref) & ref \\
\hline$T \quad 62 \quad(6)$ & 97 (11) & $1.88(1.34-2.62)$ & 0.0002 & CT & $60(12)$ & $93(21)$ & $1.98(1.39-2.82)$ & 0.0001 \\
\hline & & & & $\pi$ & $1(0)$ & $2(0)$ & $2.55(0.13-151)^{\mathrm{a}}$ & 0.822 \\
\hline
\end{tabular}

OR, odds ratio; $\mathrm{Cl}$, confidence interval; ref, used as reference; ${ }^{a}$ exact $95 \% \mathrm{Cl}$ calculated using the Fisher exact method. 
Suppl. table 5. Association analyses with hypospadias for single nucleotide polymorphisms in selected genes in the Dutch replication sample.

\begin{tabular}{lcccccc}
\hline SNP & Minor allele $^{\mathrm{a}}$ & NT & T & OR & $(95 \% \mathrm{Cl})$ & $\chi^{2} \mathbf{P}$ \\
\hline rs1934179 in DGKK & $\mathrm{A}$ & 12 & 47 & 3.92 & $(2.08-7.38)$ & $2.4 \times 10^{-5}$ \\
rs7063116 near DGKK & $\mathrm{A}$ & 12 & 46 & 3.83 & $(2.03-7.24)$ & $3.4 \times 10^{-5}$ \\
rs1880386 in GRID1 & $\mathrm{T}$ & 24 & 33 & 1.38 & $(0.81-2.33)$ & 0.233 \\
rs6607499 near KIAA2022 & $\mathrm{A}$ & 6 & 7 & 1.17 & $(0.39-3.47)$ & 0.782 \\
rs12660161 near MTHFD1L & $\mathrm{A}$ & 17 & 28 & 1.65 & $(0.90-3.01)$ & 0.101 \\
rs4705372 in PPARGC1B & $\mathrm{A}$ & 21 & 31 & 1.48 & $(0.85-2.57)$ & 0.166 \\
rs1022357 in SLCO3A1 & $\mathrm{G}$ & 28 & 37 & 1.32 & $(0.81-2.16)$ & 0.264 \\
rs10184015 in SOS1 & $\mathrm{A}$ & 19 & 18 & 0.95 & $(0.50-1.81)$ & 0.869 \\
rs3755071 in SRBD1 & $\mathrm{G}$ & 35 & 40 & 1.14 & $(0.73-1.80)$ & 0.564 \\
rs16985967 in TTC28 & $\mathrm{T}$ & 7 & 14 & 2.00 & $(0.81-4.96)$ & 0.127 \\
\hline OR, odds ratio; Cl, confidence interval; NT, minor allele not transmitted; $T$, minor \\
allele transmitted; ${ }^{a}$ the least frequent allele in the controls of the discovery \\
sample.
\end{tabular}


Suppl. table 6. Association analyses with hypospadias for single nucleotide polymorphisms in selected genes in the Swedish replication sample.

\begin{tabular}{|c|c|c|c|c|c|c|c|c|c|}
\hline & $\begin{array}{c}\text { Controls } \\
n=402 \\
n(\%)\end{array}$ & $\begin{array}{r}\text { Cases } \\
\mathrm{n}=\mathbf{2 6 6} \\
\mathrm{n}(\%) \\
\end{array}$ & OR $(95 \% \mathrm{Cl})$ & $\chi^{2} P$ & & $\begin{array}{c}\text { Controls } \\
n=402 \\
n(\%)\end{array}$ & $\begin{array}{r}\text { Cases } \\
\mathrm{n}=266 \\
\mathrm{n}(\%) \\
\end{array}$ & OR $(95 \% \mathrm{Cl})$ & $\chi^{2} P$ \\
\hline \multicolumn{5}{|c|}{ Allele frequencies } & \multicolumn{5}{|c|}{ Genotype frequencies } \\
\hline \multicolumn{5}{|c|}{ rs1934179 in DGKK } & & & & & \\
\hline G & $276(69)$ & $123(47)$ & 1.00 (ref) & ref & \multirow{2}{*}{\multicolumn{5}{|c|}{ Not applicable, X-chromosomal SNP }} \\
\hline & $124(31)$ & $137(53)$ & $2.48(1.80-3.42)$ & $2.6 \times 10^{-8}$ & & & & & \\
\hline \multicolumn{5}{|c|}{ rs7063116 near DGKK } & & & & & \\
\hline G & $284(71)$ & $137(53)$ & 1.00 (ref) & ref & \multirow{2}{*}{\multicolumn{5}{|c|}{ Not applicable, X-chromosomal SNP }} \\
\hline & $118(29)$ & $123(47)$ & $2.16(1.56-2.99)$ & $2.7 \times 10^{-6}$ & & & & & \\
\hline \multicolumn{10}{|c|}{ rs1880386 in GRID1 } \\
\hline c & $676(85)$ & $428(82)$ & 1.00 (ref) & ref & $C C$ & $288(72)$ & $179(69)$ & 1.00 (ref) & ref \\
\hline \multirow[t]{2}{*}{$T$} & $124(16)$ & $92(18)$ & $1.17(0.87-1.57)$ & 0.293 & $C T$ & $100(25)$ & $70(27)$ & $1.13(0.79-1.61)$ & 0.515 \\
\hline & & & & & $\pi$ & $12(3)$ & $11(4)$ & $1.47(0.64-3.41)$ & 0.362 \\
\hline \multicolumn{5}{|c|}{ rs6607499 near KIAA2022 } & & & & & \\
\hline G & $372(93)$ & $235(90)$ & 1.00 (ref) & ref & \multirow{2}{*}{\multicolumn{5}{|c|}{ Not applicable, X-chromosomal SNP }} \\
\hline$A$ & $29 \quad(7)$ & $27(10)$ & $1.47(0.85-2.55)$ & 0.165 & & & & & \\
\hline \multicolumn{10}{|c|}{ rs12660161 near MTHFD1L } \\
\hline G & $714(89)$ & $473(91)$ & 1.00 (ref) & ref & GG & $320(80)$ & $213(82)$ & 1.00 (ref) & ref \\
\hline \multirow[t]{2}{*}{$A$} & $84(11)$ & 49 (9) & $0.88(0.61-1.28)$ & 0.502 & $A G$ & 74 (19) & 47 (18) & $0.95(0.64-1.43)$ & 0.820 \\
\hline & & & & & $A A$ & $5(1)$ & $1(0)$ & $0.30(0.01-2.72)^{\mathrm{a}}$ & 0.473 \\
\hline \multicolumn{10}{|c|}{ rs4705372 in PPARGC1B } \\
\hline G & 709 (89) & $453(86)$ & 1.00 (ref) & ref & GG & $313(78)$ & $199(76)$ & 1.00 (ref) & ref \\
\hline \multirow[t]{2}{*}{$A$} & $89(11)$ & $73(14)$ & $1.28(0.92-1.79)$ & 0.139 & $A G$ & $83(21)$ & $55(21)$ & $1.04(0.71-1.53)$ & 0.833 \\
\hline & & & & & $A A$ & $3(1)$ & $9(3)$ & $4.72(1.16-27.3)^{\mathrm{a}}$ & 0.027 \\
\hline \multicolumn{10}{|c|}{ rs1022357 in SLCO3A1 } \\
\hline$A$ & $649(81)$ & $414(81)$ & 1.00 (ref) & ref & $A A$ & $271(68)$ & $163(63)$ & 1.00 (ref) & ref \\
\hline \multirow[t]{2}{*}{ G } & $151(19)$ & $100(19)$ & $1.04(0.78-1.38)$ & 0.794 & $A G$ & $107(27)$ & $88(34)$ & $1.37(0.97-1.93)$ & 0.073 \\
\hline & & & & & GG & $22(6)$ & $6(2)$ & $0.45(0.18-1.14)$ & 0.086 \\
\hline \multicolumn{10}{|c|}{ rs10184015 in SOS1 } \\
\hline G & $738(92)$ & $477(91)$ & 1.00 (ref) & ref & GG & $341(85)$ & $220(84)$ & 1.00 (ref) & ref \\
\hline \multirow[t]{2}{*}{$A$} & $66(8)$ & 49 (9) & $1.15(0.78-1.69)$ & 0.483 & $A G$ & $56(14)$ & 37 (14) & $1.02(0.65-1.60)$ & 0.917 \\
\hline & & & & & $A A$ & $5(1)$ & $6(2)$ & $1.86(0.47-7.79)^{\mathrm{a}}$ & 0.468 \\
\hline \multicolumn{10}{|c|}{ rs3755071 in SRBD1 } \\
\hline$A$ & $627(78)$ & $382(75)$ & 1.00 (ref) & ref & $A A$ & $241(60)$ & $143(56)$ & 1.00 (ref) & ref \\
\hline \multirow[t]{2}{*}{ G } & $173(22)$ & $130(25)$ & $1.23(0.95-1.60)$ & 0.115 & $A G$ & $145(36)$ & $96(38)$ & $1.12(0.80-1.55)$ & 0.516 \\
\hline & & & & & GG & $14(4)$ & 17 (7) & $2.05(0.98-4.28)$ & 0.053 \\
\hline \multicolumn{10}{|c|}{ rs16985967 in TTC28 } \\
\hline c & $720(90)$ & $467(90)$ & 1.00 (ref) & ref & CC & $324(81)$ & $208(80)$ & 1.00 (ref) & ref \\
\hline \multirow[t]{2}{*}{$T$} & $80(10)$ & $53(10)$ & $1.02(0.71-1.47)$ & 0.910 & $C T$ & $72(18)$ & $51(20)$ & $1.10(0.74-1.64)$ & 0.629 \\
\hline & & & & & $\pi$ & $4(1)$ & $1(0)$ & $0.39(0.01-3.98)^{a}$ & 0.710 \\
\hline
\end{tabular}

$\overline{O R}$, odds ratio; $\mathrm{Cl}$, confidence interval; ref, used as reference; ${ }^{a}$ exact $95 \% \mathrm{Cl}$ calculated using the Fisher exact method. 
Suppl. table 7. Association analyses with hypospadias for single nucleotide polymorphisms in selected genes in the discovery sample, the Dutch replication sample and the Swedish replication sample, and results of the meta-analysis.

\begin{tabular}{|c|c|c|c|c|c|c|c|c|}
\hline \multirow[b]{3}{*}{ SNP (minor allele ${ }^{a}$ ) } & \multicolumn{4}{|c|}{ Discovery sample } & \multicolumn{4}{|c|}{ Dutch replication sample } \\
\hline & \multicolumn{2}{|c|}{ MAF (\%) } & \multirow[b]{2}{*}{ OR $(95 \% \mathrm{Cl})$} & \multirow[b]{2}{*}{$\chi^{2} P$} & \multicolumn{2}{|c|}{$T D T$} & \multirow[b]{2}{*}{ OR $(95 \% \mathrm{Cl})$} & \multirow[b]{2}{*}{$\chi^{2} P$} \\
\hline & $\begin{array}{c}\text { Con- } \\
\text { trols } \\
n= \\
494\end{array}$ & $\begin{array}{c}\text { Cases } \\
n= \\
436\end{array}$ & & & NT & $\mathbf{T}$ & & \\
\hline rs1934179 in DGKK (A) & 32.9 & 54.6 & $2.5(1.9-3.2)$ & $2.5 \times 10^{-11}$ & 12 & 47 & $3.9(2.1-7.4)$ & $2.4 \times 10^{-5}$ \\
\hline rs7063116 near DGKK (A) & 29.3 & 48.3 & $2.3(1.7-3.0)$ & $2.9 \times 10^{-9}$ & 12 & 46 & $3.8(2.0-7.2)$ & $3.4 \times 10^{-5}$ \\
\hline rs1880386 in GRID1 (T) & 14.2 & 18.8 & $1.4(1.1-1.8)$ & 0.008 & 24 & 33 & $1.4(0.8-2.3)$ & 0.233 \\
\hline rs6607499 near KIAA2022 (A) & 3.7 & 7.2 & $2.0(1.1-3.7)$ & 0.018 & 6 & 7 & $1.2(0.4-3.5)$ & 0.782 \\
\hline rs12660161 near MTHFD1L (A) & 8.0 & 11.5 & $1.5(1.1-2.1)$ & 0.010 & 17 & 28 & $1.7(0.9-3.0)$ & 0.101 \\
\hline rs4705372 in PPARGC1B (A) & 13.4 & 17.7 & $1.4(1.1-1.8)$ & 0.009 & 21 & 31 & $1.5(0.9-2.6)$ & 0.166 \\
\hline rs 7085066 in SLC16A12 (C) & 9.1 & 11.0 & $1.2(0.9-1.7)$ & 0.177 & & & & \\
\hline rs1022357 in SLCO3A1 (G) & 16.4 & 20.6 & $1.3(1.0-1.7)$ & 0.020 & 28 & 37 & $1.3(0.8-2.2)$ & 0.264 \\
\hline rs10184015 in SOS1 (A) & 6.6 & 10.0 & $1.6(1.1-2.2)$ & 0.007 & 19 & 18 & $1.0(0.5-1.8)$ & 0.869 \\
\hline rs3755071 in SRBD1 (G) & 29.7 & 24.7 & $0.8(0.6-1.0)$ & 0.016 & 35 & 40 & $1.1(0.7-1.8)$ & 0.564 \\
\hline \multirow[t]{4}{*}{ rs16985967 in TTC28 (T) } & 6.3 & 11.2 & $1.9(1.3-2.6)$ & 0.0002 & 7 & 14 & $2.0(0.8-5.0)$ & 0.127 \\
\hline & \multicolumn{4}{|c|}{ Swedish replication sample } & & & \multicolumn{2}{|c|}{ Meta-analysis results } \\
\hline & \multicolumn{2}{|c|}{ MAF (\%) } & \multirow{2}{*}{\multicolumn{2}{|c|}{ OR $(95 \% \mathrm{Cl})$}} & & & \multirow[b]{2}{*}{ OR $(95 \% \mathrm{Cl})$} & \multirow[b]{2}{*}{$\chi^{2} P$} \\
\hline & $\begin{array}{c}\text { Con- } \\
\text { trols } \\
n= \\
402\end{array}$ & $\begin{array}{c}\text { Cases } \\
n= \\
266\end{array}$ & & & & & & \\
\hline rs1934179 in DGKK (A) & 31.0 & 52.7 & $2.5(1.8-3.4)$ & $2.6 \times 10^{-8}$ & & & $2.6(2.1-3.1)$ & $2.8 \times 10^{-21}$ \\
\hline rs7063116 near DGKK (A) & 29.4 & 47.3 & $2.2(1.6-3.0)$ & $2.7 \times 10^{-6}$ & & & $2.4(1.9-3.0)$ & $1.2 \times 10^{-12}$ \\
\hline rs1880386 in GRID1 (T) & 15.5 & 17.7 & $1.2(0.9-1.6)$ & 0.293 & & & $1.3(1.1-1.6)$ & 0.003 \\
\hline rs6607499 near KIAA2022 (A) & 7.2 & 10.3 & $1.5(0.9-2.6)$ & 0.165 & & & $1.6(1.1-2.4)$ & 0.011 \\
\hline rs12660161 near MTHFD1L (A) & 10.5 & 9.4 & $0.9(0.6-1.3)$ & 0.502 & & & $1.3(0.9-1.9)$ & 0.242 \\
\hline rs4705372 in PPARGC1B (A) & 11.2 & 13.9 & $1.3(0.9-1.8)$ & 0.139 & & & $1.4(1.1-1.7)$ & 0.001 \\
\hline \multicolumn{9}{|l|}{ rs 7085066 in SLC16A12 (C) } \\
\hline rs1022357 in SLCO3A1 (G) & 18.9 & 19.5 & $1.0(0.8-1.4)$ & 0.794 & & & $1.2(1.0-1.4)$ & 0.027 \\
\hline rs10184015 in SOS1 (A) & 8.2 & 9.3 & $1.2(0.8-1.7)$ & 0.483 & & & $1.3(1.0-1.7)$ & 0.075 \\
\hline rs3755071 in SRBD1 (G) & 21.6 & 25.4 & $1.2(1.0-1.6)$ & 0.115 & & & $1.0(0.7-1.4)$ & 0.952 \\
\hline rs16985967 in TTC28 (T) & 10.0 & 10.2 & $1.0(0.7-1.5)$ & 0.910 & & & $1.5(0.9-2.4)$ & 0.103 \\
\hline
\end{tabular}


Suppl. table 8. Primer and reporter sequences for the custom designed Taqman assays, ID numbers of the Taqman SNP genotyping assays, and oligonucleotide primers for the real-time PCR reactions.

\begin{tabular}{|c|c|}
\hline SNP / Gene & Sequence / Taqman SNP genotyping assay ID \\
\hline \multicolumn{2}{|c|}{ rs6607499 upstream of KIAA2022 } \\
\hline Forward primer & GAGTGGAATTTCTGGGTCATATGGA \\
\hline Reverse primer & TGGTGCAGCTTCTATGGAAAACA \\
\hline Reporter 1 & CATTTGGAGTAACTATCAGAC \\
\hline Reporter 2 & ATTTGGAGTAACTGTCAGAC \\
\hline \multicolumn{2}{|l|}{ rs7085066 in SLC16A12 } \\
\hline Forward primer & CCAGAGACCAAAATGGAACTGAAGT \\
\hline Reverse primer & AAGAGTAAGGGCGTGAAATAACCT \\
\hline Reporter 1 & CACCAACAAGAGCACC \\
\hline Reporter 2 & CACCAACAACAGCACC \\
\hline \multicolumn{2}{|c|}{ rs 7063116 upstream of DGKK } \\
\hline Assay ID & C_196656_10 \\
\hline \multicolumn{2}{|l|}{ rs1934179 in DGKK } \\
\hline Assay ID & C_12116498_10 \\
\hline \multicolumn{2}{|l|}{ rs1880386 in GRID1 } \\
\hline Assay ID & C_12127943_10 \\
\hline \multicolumn{2}{|c|}{ rs12660161 downstream of MTHFD1L } \\
\hline Assay ID & C_11414015_20 \\
\hline \multicolumn{2}{|c|}{ rs4705372 in PPARGC1B } \\
\hline Assay ID & C_27948404_10 \\
\hline \multicolumn{2}{|l|}{ rs1022357 in SLCO3A1 } \\
\hline Assay ID & C_8719491_10 \\
\hline \multicolumn{2}{|l|}{ rs10184015 in SOS1 } \\
\hline Assay ID & C_30456791_10 \\
\hline \multicolumn{2}{|l|}{ rs3755071 in SRBD1 } \\
\hline Assay ID & C_2773842_10 \\
\hline \multicolumn{2}{|l|}{ rs16985967 in TTC28 } \\
\hline Assay ID & C_34310741_10 \\
\hline \multicolumn{2}{|c|}{ GAPDH (PCR product size: 160bp) } \\
\hline Forward primer & CATGTTCGTCATGGGTGTGAACCA \\
\hline Reverse primer & AGTGATGGCATGGACTGTGGTCAT \\
\hline \multicolumn{2}{|c|}{ DGKK (PCR product size: $160 \mathrm{bp})$} \\
\hline Forward primer & AGAAGAGATGAACACCCAGGGCAA \\
\hline Reverse primer & GCAGGTTTGGCAAGGAGATGGTTT \\
\hline
\end{tabular}

bp, basepairs. 


\section{Supplementary note}

\section{Dutch discovery sample}

\section{AGORA project}

The AGORA (Aetiologic research into Genetic and Occupational/environmental Risk factors for Anomalies in children) project of the Radboud University Nijmegen Medical Centre (RUNMC), Nijmegen, The Netherlands, is building a data- and biobank with questionnaire data and DNA samples from patients with a congenital malformation or childhood cancer and their parents. For the current study, DNA was available of 679 hypospadias cases born between 1980 and 2007, collected within the AGORA biobank until 2007. All cases were living in the catchment area of this hospital, which is Nijmegen and surrounding area. The majority of the cases were of European descent (83\%), whereas descent was not European (3\%) or unknown (14\%) for the remaining cases. We excluded non-European cases from the analyses. Medical records of all cases were reviewed to identify information on syndromal hypospadias cases, to collect clinical characteristics of patients, and to determine anatomical location of the urethral opening. The location of the urethral opening was determined by experienced pediatric urologists before or during surgery. For the current study, anatomical location was subdivided into two categories: anterior and middle hypospadias (anterior cases with hypospadias sine hypospadias, glandular and (sub)coronal urethral openings and middle cases with penile urethral openings) and posterior hypospadias (cases with penoscrotal, scrotal, and perineal urethral openings). The Arnhem-Nijmegen Regional Committee on Research Involving Human Subjects approved the AGORA project. All participants and/or their parents gave written informed consent for participation in the study.

\section{Nijmegen Biomedical Study}

We obtained controls from the Nijmegen Biomedical Study, a population-based survey conducted by the Department of Epidemiology, Biostatistics and HTA and the Department of Clinical Chemistry of the RUNMC in 2003. Age and sex stratified randomly selected inhabitants of the municipality of Nijmegen $(n=22,500$ ) received an invitation to fill out a postal questionnaire on lifestyle and medical history, and to donate blood samples. The response to the questionnaire was $42 \%$ ( $n=9,373)$, whereas $72 \%(n=6,747)$ of the respondents also donated blood samples ${ }^{2}$. We selected the 596 youngest males of Dutch descent for the current study. None of them reported hypospadias or penile surgery in the questionnaires. The Arnhem-Nijmegen Regional Committee on Research Involving Human Subjects approved the Nijmegen Biomedical Study. All participants gave written informed consent for participation in the study. 


\section{Dutch replication sample}

Of the 515 cases that were assigned to one of the eight pools, only 436 could be pooled. The remaining 79 cases served as a replication sample, supplemented with 54 cases of European descent with isolated anterior or middle hypospadias collected in the AGORA project in 2008 and 2009.

\section{Swedish replication sample}

Swedish nonsyndromic hypospadias patients from the Karolinska University Hospital, Stockholm, Sweden, selected through medical records, served as a second replication sample. In total, DNA samples were collected from 356 patients for the replication study, of which we selected 266 samples from patients with anterior or middle hypospadias. DNA from 222 ethnically comparable anonymous healthy male voluntary blood donors at Karolinska University Hospital, Sweden, served as a control group, as well as 180 DNA samples from placentas taken after birth of a child without a visible malformation. The Ethics Committee at Karolinska Institutet approved the study protocol and all participants or parents gave written informed consent for participation in the study.

\section{DNA Pooling}

DNA was extracted from blood $(n=980)$ or saliva ( $n=295$, Oragene, DNA Genotek Inc.) using standard methods. We created eight case pools, after exclusion of six syndromal cases, 22 cases of non-European descent, 87 cases with posterior hypospadias, and 49 cases with unknown localization of the urethral opening. The remaining 515 cases were assigned to one of the eight pools based on the source of DNA (blood or saliva) and the localization of the urethral opening. Controls were randomly assigned to one of eight control pools.

For each pool, we diluted DNA samples to approximately $100 \mathrm{ng}^{-1} \mathrm{l}^{-1}$ in one 96-wells plate. Sixteen case samples were excluded due to low concentration $\left(<50 \mathrm{ng} \mu{ }^{-1}\right)$. Before pooling, we verified DNA integrity of the samples by gel electrophoresis. Three case and nineteen control samples showed band smearing, which is evidence of DNA degradation, and were excluded. We tested DNA quality of the diluted samples using 5' -nuclease TaqMan SNP genotyping assays for two SNPs (rs6932902 in ESR1: C_2823640_10 and rs11119982 in ATF3: C_27262262_10, Applied Biosystems). One case sample failing both assays was excluded.

Genomic DNA of each sample was quantified in triplicate using PicoGreen (Molecular Probes). We only included DNA samples from which reliable triplicate readings could be obtained, indicated by less than $10 \%$ difference between the readings, in the pools. This led to the exclusion of 59 case and 83 control samples. Finally, 436 case and 494 control samples could be pooled in eight case and eight control pools. We added equal quantities of DNA from each sample to the pools, with a minimum volume of $5 \mu \mathrm{l}$, which we considered the minimum 
volume that could be pipetted sufficiently accurately. Supplementary Figure 1 shows a flowchart of the collection, selection, and exclusion of cases for this study. Clinical characteristics of the pooled patients (discovery sample) are displayed in Supplementary Table 1.

We tested accuracy of the pools by comparing the allele frequencies of the individually genotyped SNPs (rs6932902 in ESR1 and rs11119982 in ATF3) in the individuals contributing to a pool, with the allele frequencies of these SNPs determined in the respective pool. The pools and an individual heterozygote were allelotyped using the same allele-specific Taqman probes in a real-time PCR 20 times. PCR reactions were carried out in 96-wells plates in a $10 \mu \mathrm{l}$ volume containing $10 \mathrm{ng}$ genomic DNA, $5 \mu \mathrm{l}$ Taqman Universal PCR master mix, $0.125 \mu \mathrm{l}$ assay mix and MilliQ. The PCR reaction consisted of an initial denaturation step at $95^{\circ} \mathrm{C}$ for $10 \mathrm{~min}$, followed by 40 cycles of denaturation at $92^{\circ} \mathrm{C}$ for $15 \mathrm{sec}$, and annealing and extension at $60^{\circ} \mathrm{C}$ for $60 \mathrm{sec}$. During PCR, allele-specific fluorescence was measured on an ABI 7500 FAST (Applied Biosystems). Ct values indicate the cycle time that an allele needs to produce a detectable amount of fluorescent signal. This is an indication of the initial quantity of the allele in the pool. The delta $\mathrm{Ct}$ value is the difference in cycle time that each of the alleles needs to produce a detectable amount of fluorescent signal, which is an indication of the proportion of both alleles in the pools ${ }^{3}$. We averaged delta $\mathrm{Ct}$ values in the pools across the 20 measurements and calculated allele frequencies after correcting for unequal detection of the two alleles based on the average delta $\mathrm{Ct}$ value in the heterozygote. The allele frequency determined in the individual samples differed on average only $1.2 \%$ from the allele frequency determined in the pools. Therefore, we concluded that the pools accurately reflected the allele distributions of the samples, meaning that the pools appear to be correctly constructed with equal amounts of DNA from all samples.

\section{Derivation of allele frequency estimates from microarray analysis}

We used the SNPMaP package ${ }^{4}$ in the statistical software program $R$ (http://www.Rproject.org) to calculate Relative Allele Signal (RAS) scores for each SNP from the CEL files generated by the Affymetrix GeneChip Command Console. Using this package, RAS scores were calculated by dividing the signal intensity of allele $A$ by the sum of the signal intensities of alleles $\mathrm{A}$ and $\mathrm{B}(R A S=A /(A+B))$, the method most commonly used in the literature. The signal intensities of allele $A$ and $B$ should be the same in a heterozygous individual (equivalent to a pool with a $50 \%$ allele frequency), however, due to differential amplification and hybridization, this is rarely the case. Therefore, corrections need to be made to RAS scores to generate more reliable estimates of the allele frequency. The $k$-correction factor can be calculated for each SNP using the ratio of the average signal intensities across all known heterozygotes $(k=A / B)$ to obtain a $k$-corrected raw allele frequency estimate for each SNP $\left(R A F_{k}=A /\left(A+k^{*} B\right)\right)$. We used the SNPMaP package to calculate the RAS values for each SNP from 603 healthy in-house controls of European descent assayed individually on the same genotyping platform ${ }^{1}$. Using the 
average RAS value from all individuals heterozygous for a SNP, we calculated the $k$-correction factor for each SNP. Using these $k$-correction factors, $R A F_{k}$ was calculated.

\section{Quality control}

We excluded the worst performing $5 \%$ of the measurements, indicated by the biggest difference between the $R A F_{k}$ estimates from the duplicate measurements ( $\left.>0.07\right)$. Thereafter, we averaged $R A F_{k}$ and $R A S$ across the remaining duplicate measurements to obtain estimates for each SNP.

A SNP-specific variance was calculated across the $R A F_{k}$ values of the case pools and of the control pools. Furthermore, we averaged $R A F_{k}$ values across case pools with DNA extracted from blood and case pools with DNA extracted from saliva to obtain a $R A F_{k}$ estimate for each of these two types of DNA origins. SNPs with a difference between these two estimates above the $95^{\text {th }}$ percentile $(>0.043)$ were excluded. In addition, we excluded SNPs with a variance in the case or control pools above the $95^{\text {th }}$ percentile ( $>0.0018$ or $>0.0017$, respectively) and SNPs with a minor allele frequency below $5 \%$ in the individually genotyped in-house controls. A total of 574,400 SNPs passed quality control steps and were included in the association analyses.

\section{Selection of SNPs eligible for individual genotyping in the discovery sample}

We used several criteria to select SNPs from the pooled GWAS eligible for individual genotyping in the discovery sample to validate the results. First of all, SNPs were required to appear in the top 200 ranks for all three statistical tests used, which resulted in 50 eligible SNPs (Supplementary Table 2). Secondly, SNPs had to map in or near a known gene $(<50 \mathrm{~kb}$ ), as determined by the annotation data provided by Affymetrix, leaving 32 eligible SNPs. This criterion increases the biological interpretability of findings, although we are aware of the risk of overlooking associations with intergenic SNPs that may lie in regulatory sequences or yet unknown genes. Finally, for the remaining eligible SNPs, we examined whether they were in high linkage disequilibrium (LD) $\left(r^{2}>0.8\right)$ with other SNPs on the array using data from the inhouse controls. If so, the average $P$-values from the three statistical tests were calculated for the SNPs in high LD with an eligible SNP.

We divided eligible SNPs into three groups; 1: A group with supporting evidence defined as at least half of the SNPs in high LD having a low average $P$-value $\left(<0.22\right.$, the $10^{\text {th }}$ percentile of the average $P$-values of all 574,400 SNPs), 2: A group with reduced evidence defined as at least half of the SNPs in high LD having a high average $P$-value, and 3: A group with no supporting evidence because of no SNPs in high LD. For individual genotyping in the discovery sample, we selected the fourteen eligible SNPs with supporting evidence and the four eligible SNPs with no supporting evidence, but with a minor allele frequency above $10 \%$ in the individually genotyped in-house controls. Furthermore, we selected two additional SNPs with no supporting evidence, the SNPs near MTHFD1L and DIAPH3, because we considered these to be 
promising functional candidate genes. DIAPH3 is an important factor in epithelial cell migration $^{5}$, and a previous study suggested an association of hypospadias with intake of certain nutrients related to one-carbon metabolism ${ }^{6}$, in which the MTHFD1L gene plays a role. Thus, 20 SNPs were eligible for individual genotyping in the discovery sample.

\section{Expression of DGKK}

\section{Preputial skin samples}

Excess preputial skin was obtained from fourteen patients with hypospadias undergoing surgical repair and from ten age-matched controls undergoing elective circumcision between January 2004 and June 2004 at the Department of Urology of the University of California, San Francisco, CA, USA. Patients with undescended testis, intersex condition or known endocrine abnormalities were excluded from the study. No patients received preoperative testosterone treatment. The institutional Committee on Human Research at the University of California, San Francisco approved this study and all parents gave written informed consent for participation in the study.

\section{RNA preparation, reverse transcription and real-time PCR}

We isolated RNA from the preputial skin samples using the QIAGEN RNeasy Midi Kit (QIAGEN Inc.). The manufacturer's protocol was modified to eliminate any contaminating protein and DNA by adding Proteinase $\mathrm{K}$ (Roche Diagnostics $\mathrm{GmbH}$ ) and incubation at $55^{\circ} \mathrm{C}$ for $20 \mathrm{~min}$, and by adding RNase-free DNase I (QIAGEN Inc.), which was incubated at room temperature for 15 min. RNA quantity and purity were measured using a Nanodrop spectrophotometer (Thermo Fisher Scientific Inc.) and RNA integrity was visualized in agarose gels by the $28 \mathrm{~s}$ and $18 \mathrm{~s}$ ribosomal RNA bands. We performed the reverse transcription (RT) polymerase chain reaction (PCR) according to the standard protocol. Briefly, $2.5 \mu \mathrm{g}$ RNA was reverse transcribed in a $20 \mu \mathrm{l}$ reaction volume and RT products were diluted 4-fold with TE buffer (10 mM Tris- $\mathrm{HCl}, \mathrm{pH} 8,1$ mM EDTA).

We designed real-time PCR primers according to target gene sequences published in the NCBI nucleotide sequence database (Supplementary Table 8) and these were synthesized by Integrated DNA Technologies Inc. Real-time PCR was performed in a $20 \mu \mathrm{l}$ reaction volume containing 20 ng template DNA, $1 \times$ Power SYBR Green PCR master mix (Applied Biosystems) and $300 \mathrm{nM}$ primers. Amplification was carried out in 96-wells plates in a 7300 Fast sequence detection system (Applied Biosystems) with the manufacturer's default thermal profile $\left(50^{\circ} \mathrm{C}\right.$ for $2 \mathrm{~min}, 95^{\circ} \mathrm{C}$ for $10 \mathrm{~min}$, and $40 \mathrm{cycles}$ of $95^{\circ} \mathrm{C}$ for $15 \mathrm{sec}$ and $60^{\circ} \mathrm{C}$ for $1 \mathrm{~min}$ ) followed by a dissociation stage $\left(95^{\circ} \mathrm{C}\right.$ for $15 \mathrm{sec}, 60^{\circ} \mathrm{C}$ for $15 \mathrm{sec}$, followed by a slow ramp to $\left.95^{\circ} \mathrm{C}\right)$. We performed primer titration and dissociation experiments to prevent primer dimers or false amplicons from interfering with the result. After the RT PCR experiment, Ct numbers were extracted for both the reference gene and the target gene with auto baseline and manual 
threshold using standard 7300 Fast software. Expression levels of $D G K K$ were reported relative to GAPDH. We repeated the PCR three times for each sample and averaged results across the three measurements when no exceptional outliers were seen. Consequently, two samples were averaged across two measurements.

\section{References}

1. Franke B, Arias Vasquez A, Veltman JA, Brunner HG, Rijpkema M, Fernández G. Genetic variation in CACNA1C, a gene associated with bipolar disorder, influences brainstem rather than gray matter volume in healthy individuals. Biol Psychiat 2010:68;586-588.

2. Hoogendoorn EH, Hermus AR, de Vegt F, Ross HA, Verbeek ALM, Kiemeney LALM, Swinkels DW, Sweep FCGJ, den Heijer M. Thyroid function and prevalence of anti-thyroperoxidase antibodies in a population with borderline sufficient iodine intake: influences of age and sex. Clin Chem 2006:52;104-111.

3. Germer S, Holland MJ, Higuchi R. High-throughput SNP allele-frequency determination in pooled DNA samples by kinetic PCR. Genome Res 2000:10;258-266.

4. Davis OSP, Plomin R, Schalkwyk LC. The SNPMaP package for R: a framework for genomewide association using DNA pooling on microarrays. Bioinformatics 2009:25;281-283.

5. Gupton SL, Eisenmann K, Alberts AS, Waterman-Storer CM. mDia2 regulates actin and focal adhesion dynamics and organization in the lamella for efficient epithelial cell migration. $J$ Cell Sci 2007:120;3475-3487.

6. Carmichael SL, Yang W, Correa A, Olney RS, Shaw GM. Hypospadias and intake of nutrients related to one-carbon metabolism. J Urol 2009:181;315-321. 